Board of Governors of the Federal Reserve System

International Finance Discussion Papers

Number 559

July 1996

\title{
BROAD MONEY DEMAND AND FINANCIAL LIBERALIZATION IN GREECE
}

Neil R. Ericsson and Sunil Sharma

NOTE: International Finance Discussion Papers are preliminary materials circulated to stimulate discussion and critical comment. References in publications to International Finance Discussion Papers (other than an acknowledgment that the writer has had access to unpublished material) should be cleared with the author or authors. 


\begin{abstract}
This paper develops a constant, data-coherent, error correction model for broad money demand (M3) in Greece. This model contributes to a better understanding of the effects of monetary policy in Greece, and of the portfolio consequences of financial innovation in general. The broad monetary aggregate M3 was targeted until recently, and current monetary policy still uses such aggregates as guidelines, yet analysis of this aggregate has been dormant for over a decade.

In spite of large fluctuations in the inflation rate, introduction of new financial instruments, and liberalization of the financial system, the estimated model is remarkably stable. The dynamics of money demand are important, with price and income elasticities being much smaller in the short run than in the long run.
\end{abstract}

Keywords: broad money, cointegration, conditional models, dynamic specification, error correction, exogeneity, financial liberalization, financial innovation, general-to-specific modeling, Greece, money demand, sequential reduction, vector autoregression. 


\title{
Broad Money Demand and Financial Liberalization in Greece
}

\author{
Neil R. Ericsson and Sunil Sharma*
}

\section{Introduction}

Recent changes in the Greek financial system pose challenges for the conduct of monetary policy. The removal of most external capital controls and the abolition of restrictions on the portfolios of deposit-taking institutions have substantially changed the environment in which monetary policy operates. The interbank market has deepened, interest rates are more flexible, and new indirect instruments of monetary control are being developed.

At the operational level, the monetary program prepared by the Bank of Greece at the beginning of each year defines the monetary policy of the authorities. Until recently, its formulation focussed on the determination of the appropriate growth of broad money (M3) on the basis of projections for real output growth, inflation, interest rates, and the desired external balance. ${ }^{1}$ From the projected path of M3, an estimate of the required increase in net domestic credit was calculated. Given a separate assessment of the credit needs of the private sector, the Bank could derive the credit expansion to the public sector that was consistent with these projections.

In light of fundamental changes to the financial system, the monetary authorities have recently shifted to targeting the exchange rate. ${ }^{2}$ New financial products have complicated the choice of an appropriate monetary aggregate as a target. Besides requiring redefinition of what constitutes "money," these products have changed the characteristics of assets that were previously included in the monetary aggregates. Although easier to control, narrowly defined aggregates are less useful in policy, as their relationship with nominal income appears subject to considerable variability. Broader aggregates appear more stable relative to nominal income, but they are less amenable to control. In addition, Greece's differential taxation of financial products has complicated the assessment of movements

* The authors are staff economists in the Division of International Finance, Federal Reserve Board, and the Research Department, International Monetary Fund, respectively. The views expressed in this paper are solely the responsibility of the authors and should not be interpreted as reflecting those of the Board of Governors of the Federal Reserve System, the International Monetary Fund, or other members of their staffs. We wish to thank Sophocles Brissimis, Nicholas Paleocrassas, and George Simigiannis at the Bank of Greece for providing the data and offering insights into institutional aspects of the Greek financial system; and Richard Agenor, Caroline Atkinson, Adi Brender, Julia Campos, Dimitri Demekas, David Hendry, Tim Lane, and Jaime Marquez for useful discussions and comments. This paper is being simultaneously circulated as IMF Working Paper No. WP/96/62 by the International Monetary Fund and International Finance Discussion Paper No. 559 by the Board of Governors of the Federal Reserve System.

1 The Bank of Greece also monitors a broader measure of liquidity, M4, which is defined as M3 plus government paper with maturity of up to a year.

2 In 1995, the authorities' monetary program announced a targeted rate of crawl of the Drachma/ECU exchange rate for the first time. Ranges for M3 and M4 growth were also specified to serve as guidelines. 
in monetary aggregates.

The purpose of this paper is to model the empirical relationship between broad money, prices, real output, and interest rates, and to examine the constancy of this relationship, especially in light of recent changes in the financial system. In spite of its importance for forecasting and policy, constancy has proved elusive for estimated money demand functions of many countries; see Judd and Scadding (1982) for the United States. While nonconstant empirical equations do not preclude a stable underlying relation, they leave unresolved the question of whether the observed predictive failure arises from shifts in the underlying relation or whether it is simply a consequence of model misspecification.

For Greek money demand, that question is moot. The estimated model is remarkably constant in spite of large fluctuations in the inflation rate, the introduction of new financial instruments, and liberalization of the financial system. The long-run demand for real money depends upon real income with a unit elasticity, and on the own interest rate with a semi-elasticity of approximately five. Assets outside money affect money demand through a spread between their rate of return and the rate of return on broad money. The dynamics of money demand are important, with price and income elasticities being much smaller in the short run than in the long run.

This paper is organized as follows. Section II presents a brief historical perspective and discusses the economic theory of money demand and the data available. Section III analyzes integration and cointegration properties of the data, testing for cointegration and weak exogeneity in a six-variable vector autoregression. The evidence on cointegration ties back directly to the economic theory of money demand. The empirical weak exogeneity of prices, income, and interest rates provides the foundation for development of a parsimonious, empirically constant, single-equation error correction model for money demand in Section IV. Section IV also examines the stability of the estimated money demand function in the face of financial liberalization over the period under consideration. Section V discusses some caveats and implications of the results, and Section VI concludes. Appendix I describes the construction of the data, and Appendix II documents the design of the empirical error correction model. ${ }^{3}$

3 The data can be obtained by request from the authors at Internet addresses ericsson@frb.gov and ssharma@imf.org. All numerical results were obtained using PcGive Professional Versions 8.10, 8.15, and $9.00 \beta$; cf. Doornik and Hendry (1994). We are especially grateful to Jurgen Doornik and David Hendry for providing us with an update to PcGive Professional (Version 8.15) and a pre-release version of PcGive Professional for Windows (Version 9.00 $\beta$ ) . 


\section{Background}

This section provides the backdrop for the empirical modeling in Sections III-V. It summarizes important economic events over the sample period (Section II.1), sketches the static theory-model for money demand (Section II.2), describes the data available and some of their basic properties (Section II.3), and relates the theory model to the observed data (Section II.4).

\section{A Historical Perspective}

In the 1970s and early 1980s, the Greek financial system was very strictly regulated. Funds were allocated at administratively set interest rates through a complicated reserve/rebate system of bank credit. Compulsory investment requirements for banks channeled funds into certain sectors of the economy at subsidized rates, with below-market financing of the government and tight foreign exchange controls. This subsection summarizes the evolution of financial instruments available and the financial liberalizations and innovations of the 1980s and 1990s. See Alogoskoufis (1995) and Soumelis (1995) for recent overviews.

Between 1980 and 1987, financial liberalization evolved gradually. In 1982, the responsibility for the formulation and conduct of monetary policy was transferred from the Monetary Committee to the Bank of Greece, and credit to the government was limited to 10 percent of the current year's budgeted expenditures. By 1984, administratively set interest rates on loans to the private sector had been reduced to three basic categories: long-term investment; working capital; and housing, small-scale industry, and agriculture. Interest rates on government paper were gradually raised to levels comparable with bank deposit rates and, in 1985, sales of Treasury bills directly to the public were resumed after a long hiatus. In 1986, the sale of medium-term, Drachma-denominated, foreign exchange-linked bonds was resumed, and restrictions on foreign participation in these instruments were lifted.

Deregulation of the financial system then accelerated, following the 1987 Report of the Committee for the Reform and Modernization of the Greek Banking System. In November 1987, interest rates on time deposits were deregulated, and banks were allowed to offer certificates of deposit and bank bonds at market rates. Interest rates were also deregulated on most categories of short-term and long-term loans, which accounted for over 80 percent of bank lending to the private sector. The reserve/rebate system used for allocating bank credit was abolished in December 1988. In 1989, the setting of savings deposit rates was liberalized, but they were still subject to a minimum rate established by the Bank of Greece. This last control on deposit rates was abolished in March 1993. Along with direct credit restrictions and reserve requirements on banks, this minimum rate had been an important instrument of monetary control in the previous decade. 
Many credit restrictions have been removed in the 1990s as well. In the 1970s and 1980s, banks were required to invest a certain fraction of their total deposits in shortterm government paper, that fraction being 40 percent as late as 1990. This investment requirement was gradually reduced during 1991-1993, and in May 1993 it was abolished. Similar changes have occurred to the requirement that commercial banks earmark a proportion of their total deposits for financing the small-scale sector. This proportion, which was 10 percent at the beginning of 1991, declined over 1991-1993 and was dropped in July 1993.

The banking law of August 1992 instituted further important reforms of the financial sector. In addition to adopting the relevant EC directives (Second Banking, Prospectus, Insider Dealing, Admission of Securities, and Major Holdings), the law introduced several wide-ranging changes. First, the law further blurred the distinction between commercial banks and specialized credit institutions, allowing the latter to expand into financial activities previously forbidden to them, e.g., leasing, credit cards, and foreign exchange loans. Second, it limited central bank advances to the government in 1993 to no more than 5 percent of the budgeted increase in expenditures. Third, it stipulated that banks must stop accruing interest on loans that have not been serviced for 12 months, and it prevented banks from granting new loans to repay overdue interest. Fourth, it reduced government control over state-owned commercial banks by suspending the right of the Finance Minister to vote in their shareholders' meetings on behalf of public entities that also hold shares. Fifth, it established a Capital Market Commission to supervise the Athens Stock Exchange.

At the beginning of 1994, monetary financing of the government and privileged government access to the central bank were abolished, as mandated by the Maastricht Treaty. Constraints on bank intermediation were further reduced: the turnover tax on interest from bank loans was halved (to 4 percent), and restrictions on consumer credit were removed.

In the 1990s, financial deregulation proceeded in tandem with a significant liberalization of external transactions. In May 1991, restrictions on long-term capital movements vis-à-vis EC countries were lifted, including restrictions on the purchase of real estate. In January 1992, restrictions were removed on the withdrawal of funds from blocked accounts, and on the international transfer by non-EC residents of Greek pensions, Greek rents, and profits from investments undertaken in Greece. In July 1992, payments and transfers relating to current account transactions were completely liberalized. Capital movements were completely deregulated in March 1993, excepting financial credits and personal loans with original maturity of less than a year. All remaining short-term controls on external capital movements were abolished in May 1994.

Financial deregulation, coupled with changing and differential taxation of financial instruments, complicates the assessment of movements in monetary aggregates. Extension 
of withholding tax to earnings on repurchase agreements (repos) precipitated a massive flight out of that asset. This flight occurred for two reasons. First, withholding tax was applied to repos but not government securities, which then offered a more attractive return. Second, financial liberalization allowed the creation of products called "synthetic swaps." These derivatives reduce the tax liability on interest from Drachma deposits by simultaneously swapping Drachmas for foreign currency (with a lower interest rate and hence a lower tax liability) and entering into a forward agreement to purchase Drachmas with the foreign currency deposit at maturity.

The new policy environment has entailed a move to indirect instruments of monetary control. Since September 1993, the buying and selling of government bonds between the Bank of Greece and credit institutions (with or without a repurchase agreement) has been permitted so as to facilitate and expand money market interventions by the central bank. Two credit facilities were introduced by the Bank of Greece in mid-1993 for the temporary financing needs of commercial banks: a Lombard facility for short-term financing using government securities as collateral, and a facility for rediscounting promissory notes and bills of exchange. While the discount facility had existed earlier, it had not been used; and the total amount that banks could borrow through it was increased. See Filippides, Kyriakopoulos, and Moschos (1995) for further discussion.

Because the financial sector was highly regulated and external capital movements were controlled over much of the sample, two points should be emphasized when modeling money demand. First, the range of available financial instruments was very limited until 1985, when sales of Treasury bills to the public resumed. Even then, real assets constituted a substantial part of an investor's portfolio, so inflation (a proxy for their rate of return) may be an important determinant of money demand. Second, although government paper of various maturities became available in the late 1980s and early 1990s, the interest rates on these instruments were closely linked to the key one-year Treasury bill rate. Thus, that one-year rate is used to proxy the return on financial assets outside of M3.

\section{Economic Theory}

Money is demanded for at least two reasons: as an inventory to smooth differences between income and expenditure streams, and as one among several assets in a portfolio; see Baumol (1952), Tobin (1956), and Friedman (1956). The transactions motive implies that nominal money demand depends on the price level and some measure of the volume of real transactions. Holdings of money as an asset are determined by the return to money as well as returns on alternative assets, and by total assets (often proxied by income). These determinants lead to a long-run specification in which nominal money demanded $\left(M^{d}\right)$ depends on the price level $(P)$, a scale variable $(Y)$, and a vector ( $\mathbf{R}$, in bold) of rates of returns on various assets: 


$$
\begin{gathered}
-6- \\
M^{d} / P=q(Y, \mathbf{R}) .
\end{gathered}
$$

The function $q(\cdot, \cdot)$ is assumed increasing in $Y$, decreasing in those elements of $\mathbf{R}$ associated with assets excluded from money $(M)$, and increasing in those elements of $\mathbf{R}$ for assets included in $M$. Equation (1) imposes unit price homogeneity, which could be tested empirically.

Commonly, (1) is specified in log-linear form, albeit with the interest rates entering in their levels. Sections III-V assume such a specification below, where the competing assets are Drachma (Dr) broad money as measured by M3, Drachma Treasury bills, and domestic goods. The corresponding rates of return are the net interest rates on time deposits $R T^{n}$ and on repos $R R^{n}$ (both being returns on components of M3), the interest rate on Treasury bills $R B$, and the inflation rate $\Delta p$ respectively. The rates $R T^{n}, R R^{n}$, and $R B$ are described at greater length below, $\Delta$ is the first difference operator, and variables in lower case denote logarithms. ${ }^{4}$ In light of the financial structure and data properties described elsewhere in this section, this choice of assets and returns seems reasonable. Thus, (1) may be written explicitly as:

$$
m^{d}-p=\gamma_{0}+\gamma_{1} y+\gamma_{2} R T^{n}+\gamma_{3} R R^{n}+\gamma_{4} R B+\gamma_{5} \Delta p .
$$

Anticipated signs of the coefficients are $\gamma_{1}>0$ (specifically, $\gamma_{1}=1$ for the quantity theory of money), $\gamma_{2}>0, \gamma_{3}>0, \gamma_{4}<0$, and $\gamma_{5}<0$.

Economic theory offers little guidance in modeling the behavior of money out of equilibrium, beyond saying that adjustments to "desired" levels of money holdings are not likely to be instantaneous due to adjustment costs. Further, empirical specifications that unduly restrict short-term dynamics may contaminate the estimation of the long-run specification itself. Sections III-V develop a dynamic error correction model (ECM) of broad money demand, allowing the economic theory above to define the long-run equilibrium while determining short-run dynamics from the data. A similar approach to modeling money demand is adopted in Boughton (1991, 1993), Hendry and Ericsson (1991a, 1991b), Baba, Hendry, and Starr (1992), and Hendry and Starr (1993); see also Hendry (1995).

\section{The Data}

The data used are as follows. Money $M$ is the broad measure M3 (Dr billion), $P$ is the consumer price index $(1970=100), Y$ is real income (Dr billion, gross domestic product at factor cost in 1970 prices), and $\mathbf{R}$ contains rates of returns on assets within

\footnotetext{
${ }^{4}$ The difference operator $\Delta$ is defined as $(1-L)$, where the lag operator $L$ shifts a variable one period into the past. Hence, for $x_{t}$ (a variable $x$ at time $t$ ), $L x_{t}=x_{t-1}$ and so $\Delta x_{t}=x_{t}-x_{t-1}$. More generally, $\Delta_{j}^{i} x_{t}=\left(1-L^{j}\right)^{i} x_{t}$. If $i$ (or $j$ ) is undefined, it is taken to be unity.
} 
and outside of broad money. The data span the period 1975-1994 and were obtained from the Bank of Greece. All series are quarterly, seasonally unadjusted. The data were not seasonally adjusted because such pre-filtering may affect short-term dynamics; see Wallis (1974) and Ericsson, Hendry, and Tran (1994). Rather, seasonality is captured explicitly in estimation by including seasonal dummies and (initially) seasonal lags in the set of regressors. This subsection sequentially discusses money, prices, income, and the rates of return, where the latter are compared with their corresponding assets. Appendix I considers the definition and construction of the data in detail.

Figure 1 plots the logarithms of money and prices ( $m$ and $p$ ), with the latter adjusted to match the mean of the former. The price level is measured by the consumer price index ( $1970=100$, but based on 1988 consumption weights) because a quarterly series for the GDP deflator is not available. Figure 2 plots the logarithm of real M3 $(m-p)$, showing that real M3 grew at approximately $6 \%$ per annum through 1989 and remained relatively constant thereafter. One possible explanation for the reduction in the growth rate, examined below, is the increased availability of assets outside M3 and the deregulation of the financial system. Figures 3 and 4 respectively graph the quarterly and annual growth rates of money and prices. Strong seasonality is apparent in the quarterly growth rates, whereas the annual values clarify the general decline in the growth rates of both nominal and real money over the sample.

The scale variable $Y$ is proxied by gross domestic product (GDP) at factor cost in constant 1970 prices: this is the only real output variable for which a quarterly series is available. The Bank of Greece recently revised the GDP series from 1987, in line with the new annual national accounts (base year 1988) published by the National Statistical Service of Greece. These revisions strongly affected the seasonal pattern from 1989 onwards. Figure 5 plots real GDP on this new basis, along with the unrevised series $\left(Y^{o l d}\right)$. The latter series has been published by the National Statistical Service only through 1991(1), and its constant seasonal pattern highlights the difference between the two series. While the new GDP series appears to be the best currently available, its break in seasonal pattern does complicate matters econometrically. To allow for this change in measured seasonality, estimation of the money demand relation initially includes seasonal dummies for 1989 onwards in addition to seasonal dummies spanning the whole sample. In the final parsimonious ECM, the subsample seasonal dummies are statistically unnecessary and so are not included.

Velocity can be constructed from real GDP and real money: Figure 6 plots the annual growth rates of both these variables. While high money growth is coincident with a rapidly growing economy in the late 1980s, there are numerous other periods when the movements of the two variables appear unrelated. One potential explanation is the role of additional variables in the money demand relation and, in particular, of rates of return.

From the economic theory discussed in Section II.2, money demand depends upon 


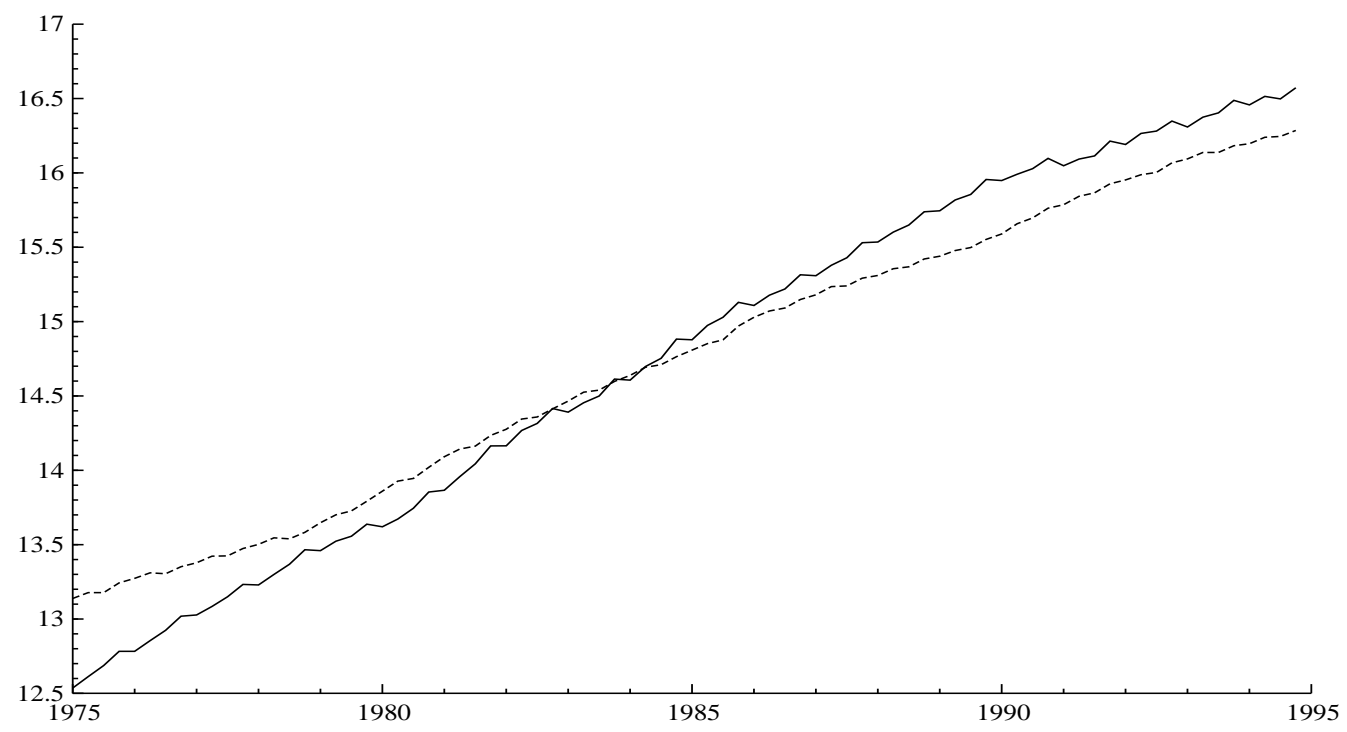

Figure 1: Logarithms of broad money $m(-)$ and the consumer price index $p(---)$.

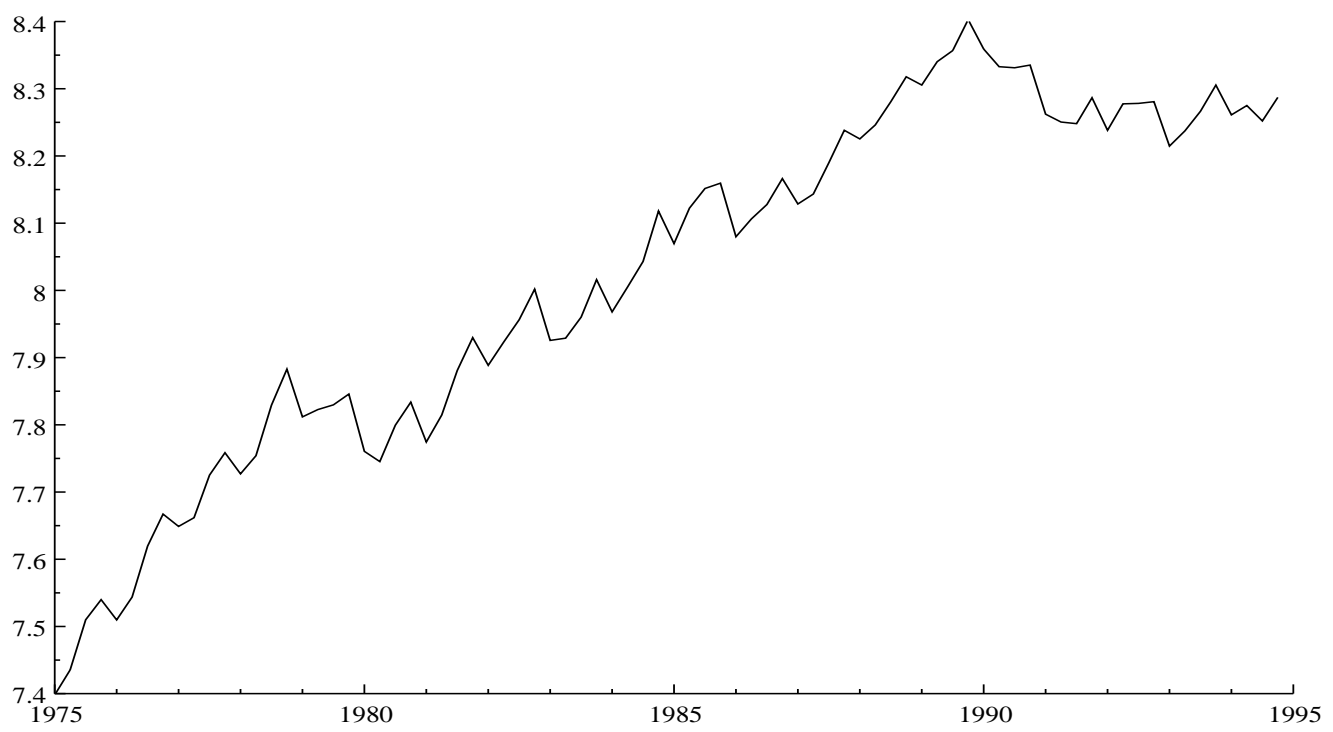

Figure 2: The logarithm of real money $m-p$. 


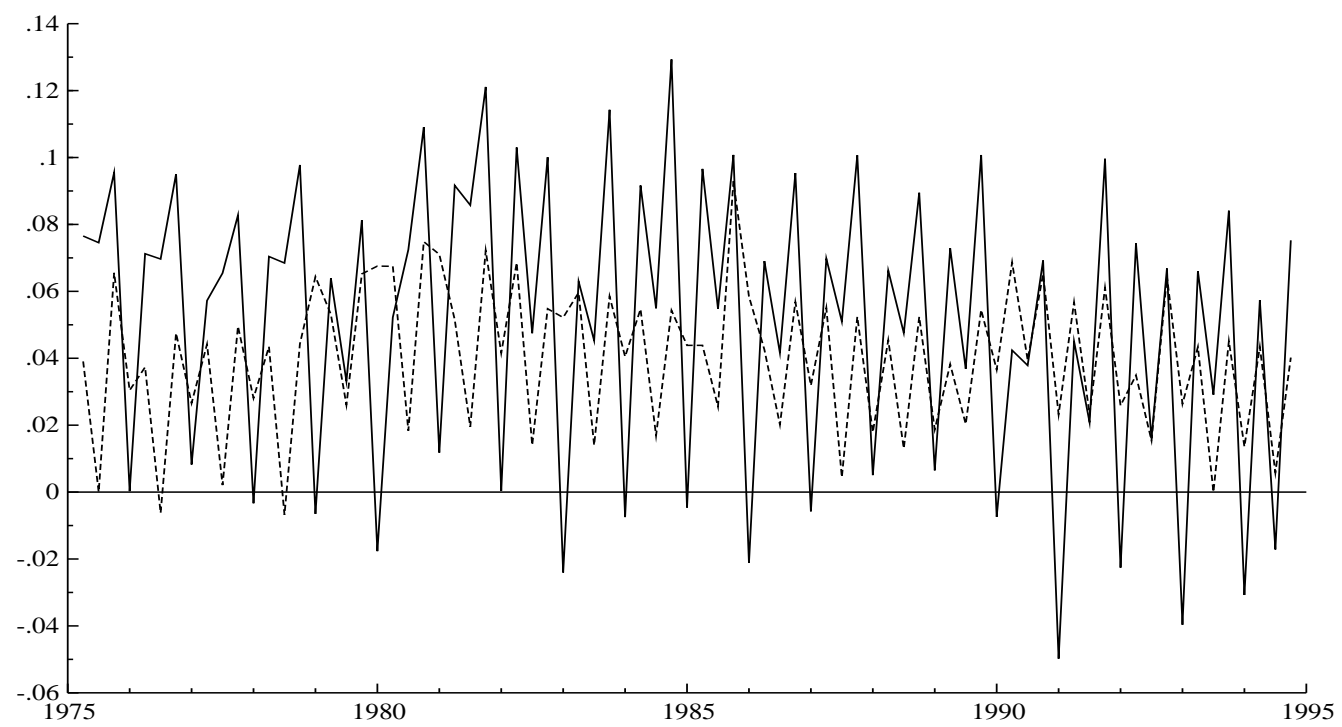

Figure 3: The quarterly growth rate of M3 $(\Delta m:-)$ and the quarterly inflation rate ( $\Delta p:--$-).

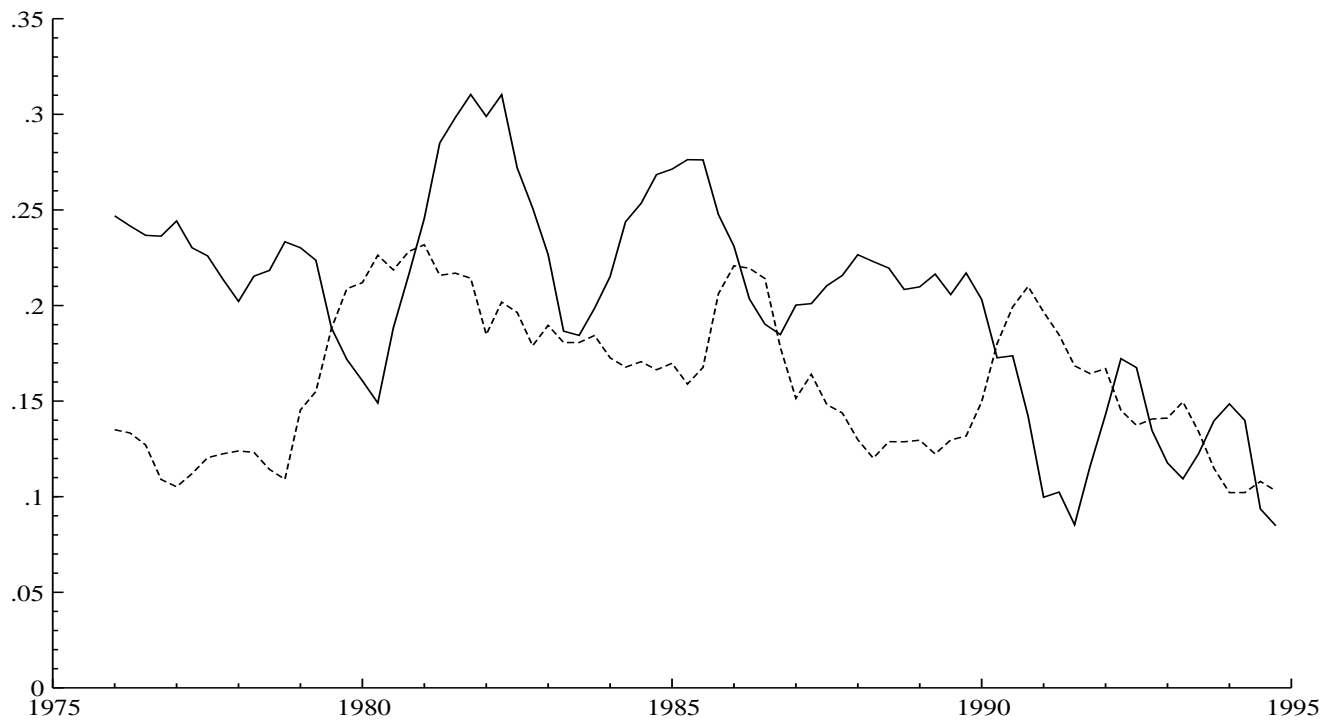

Figure 4: The annual growth rate of M3 $\left(\Delta_{4} m:-\right)$ and the annual inflation rate $\left(\Delta_{4} p:--\right)$. 


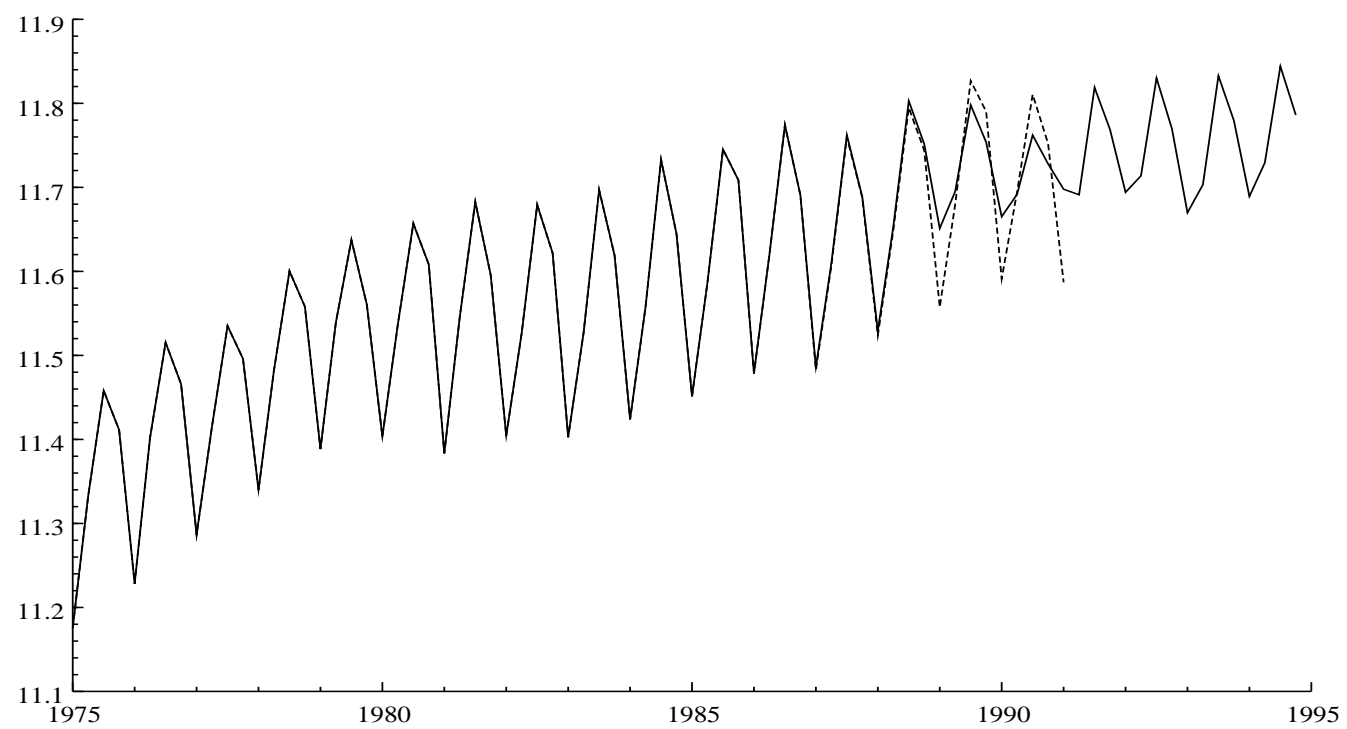

Figure 5: Logarithms of real GDP on the new basis $(y:-)$ and the old basis ( $\left.y^{\text {old }}:---\right)$.

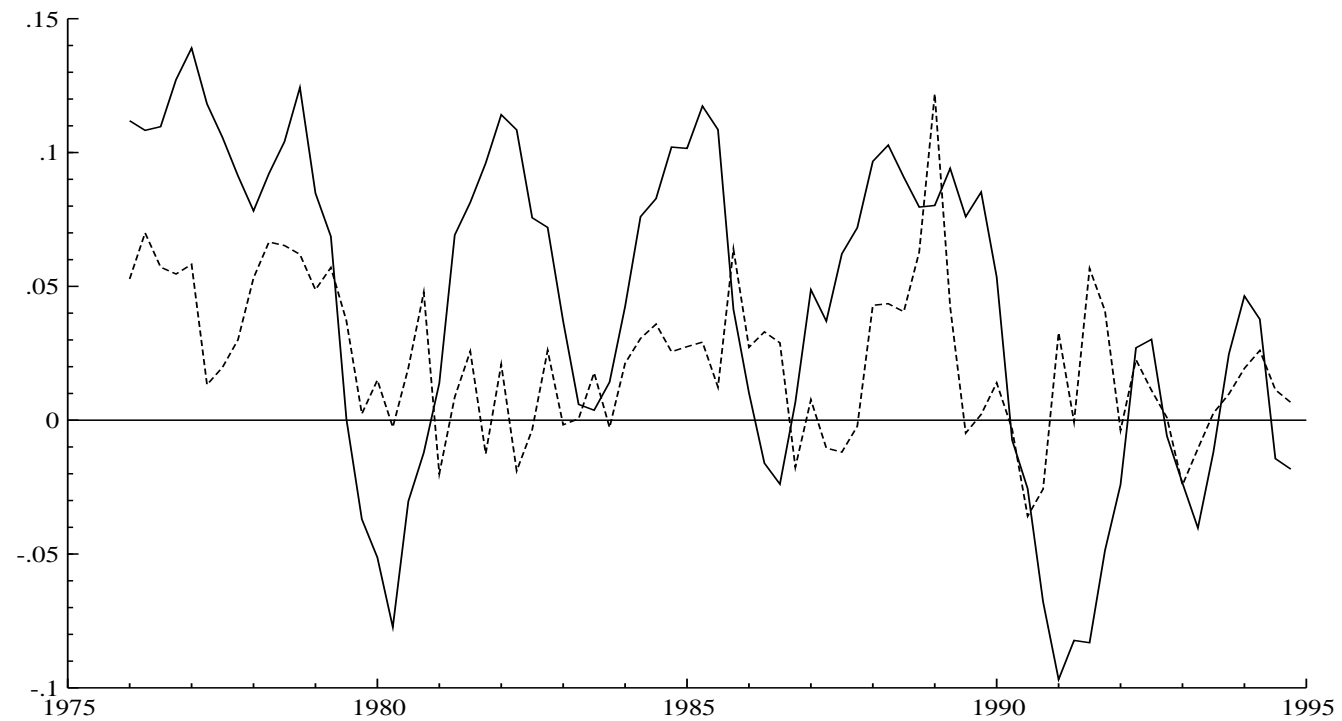

Figure 6: The annual growth rates of real M3 $\left[\Delta_{4}(m-p)\right.$ : - $]$ and real GDP ( $\left.\Delta_{4} y:---\right)$. 
both own rates of return and outside rates of return. A distinct asset corresponds to each rate of return, with movements in the rates of return influencing the holdings across the various assets. With that in mind, the remainder of this subsection considers various competing assets in Greece and their rates of return.

Broad money may be decomposed into several assets, with each asset offering a possibly different (own) rate of return. For Greece, the relevant components of M3 are: currency in circulation $(C C)$, private demand deposits $(D D)$, private savings deposits $(S D)$, time deposits $(T D)$, bank bonds $(B B)$, and repurchase agreements (repos, denoted $R E P$ ). Figure 7 graphs these components, cumulatively. Narrow money (M1) is the sum of the first two components $(C C+D D)$, and $\mathrm{M} 3$ is the sum of all six components.

Each component of M3 has an associated nominal rate of return: zero for currency, $R D$ for demand deposits, $R S$ for savings accounts, $R T$ for time deposits, and $R R$ for repos. $^{5}$ Figure 8 plots the annual rate of inflation $\Delta_{4} p$ and the four nonzero rates of return, where the rates are in percent per annum, expressed as fractions. For much of the period until mid-1986, all ex post real interest rates were negative. Thereafter, ex post real returns on savings and time deposits were positive, except for a brief interlude around 1990 when inflation again reached 20 percent. Repos were introduced in 1990 and have offered rates of return competitive with time deposits.

Time deposits and repos offer the highest rates of return on the components of M3 described above, so $R T$ and $R R$ are natural proxies for the own (marginal) rate for M3. For that reason, and in order to limit the number of variables examined, $R D$ and $R S$ are excluded from the econometric analysis in Sections III-V.

One adjustment to rates on components of M3 appears economically and statistically important. In 1991(1), the government introduced a 10 percent withholding tax on interest from bank deposits, increasing the tax in mid-1992 to 15 percent. In April 1994, this tax was extended to cover returns from repurchase agreements. Thus, the after-tax returns on these assets (denoted $R T^{n}$ and $R R^{n}$ ) seem relevant to individuals' decisions about money holdings. ${ }^{6}$

5 The interest rate on bank bonds is not currently available. However, as Figure 9 below shows, the fraction of bank bonds in M3 changes only very slowly over time and is never greater than $8 \%$.

That said, repos, introduced at the end of 1990, have become an increasingly important source of funds for deposit institutions. In 1992, the Bank of Greece redefined M3 to include bank bonds and repos, using this new measure to set the M3 targets in its monetary program. We use that new definition of broad money for the entire sample period.

6 Changes in the institutional structure and the tax system also could affect the relative returns on existing and new assets and hence the demand for money. For instance, the efficiency of collection (and the ease of avoidance) of the withholding tax on interest income could be important. In the United States, such witholding tax is easily avoided, but avoiding eventual payment of tax on interest income is more difficult because banks are required to report interest earnings to the Internal Revenue Service. 


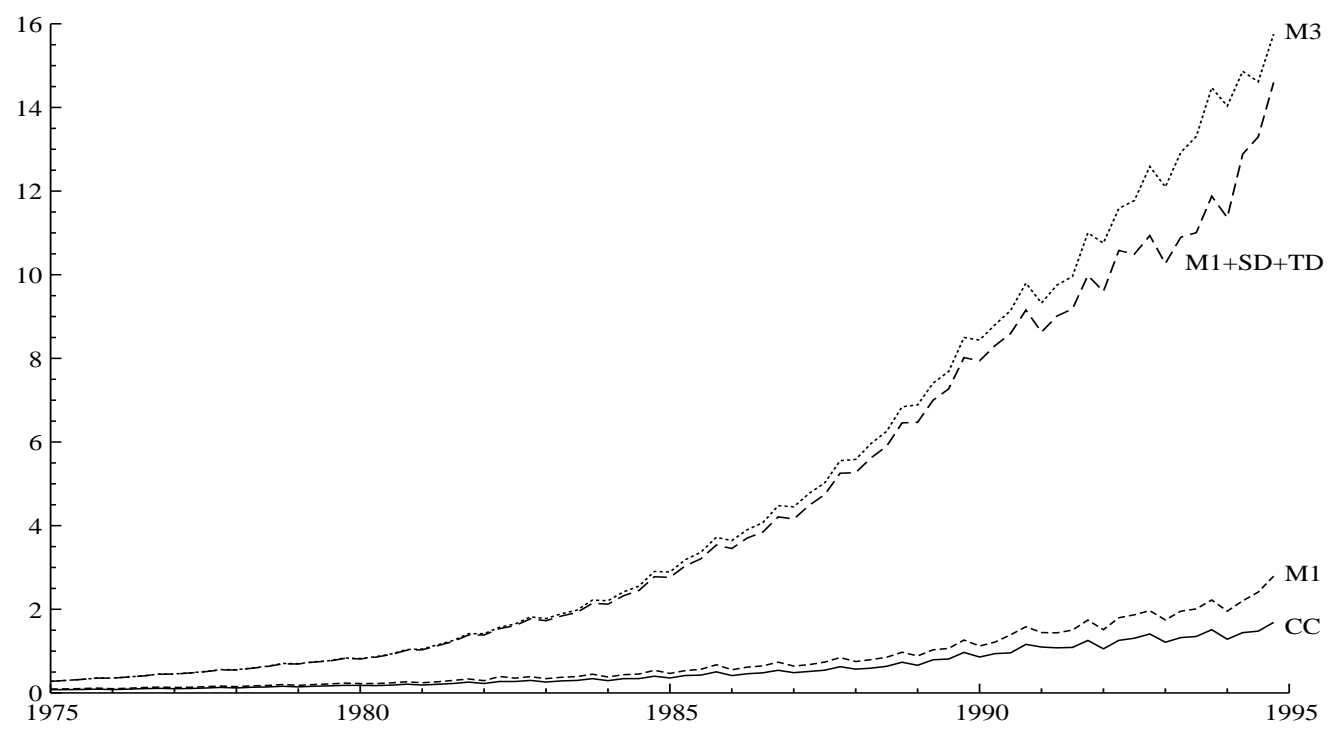

Figure 7: Cumulated components of broad money: currency in circulation $C C(-)$, M1 (- - ), M1 $+S D+T D(--)$, and M3 ( . ), all in trillions of Drachmas.

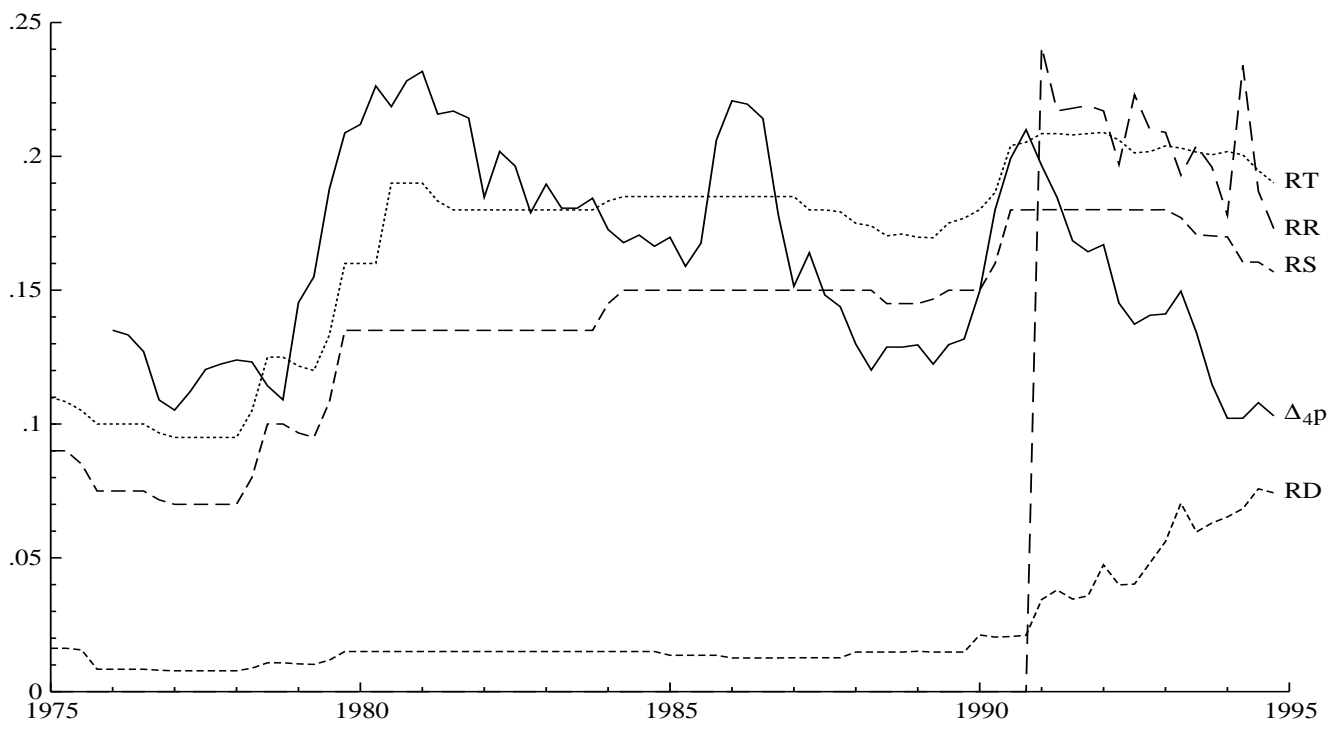

Figure 8: Inflation $\Delta_{4} p(-)$, and interest rates on demand deposits (RD: - - ), savings deposits $(R S:--)$, time deposits $(R T: \cdots)$, and repos $(R R:-\longrightarrow)$. 
Figure 9 graphs the fractions in M3 of M1 $[(C C+D D) / M]$, savings and time deposits $[(S D+T D) / M]$, and repos $[R E P / M]$. Figure 10 plots the corresponding net rates of return, $R D^{n}, R T^{n}$, and $R R^{n}$. These represent the highest interest rates offered on the respective components of M3. The fraction of M1 declined steadily through 1989, reflecting in part the increased yield on savings and time deposits relative to demand deposits. With their deregulation, demand deposit rates increased in the 1990s, and the fraction of M1 in M3 stabilized. The fraction of savings and time deposits increased through the 1980s, mirroring the decline in the fraction of M1. During the 1990s, the fraction of savings and time deposits fell for two reasons: the development of the repo market, where repos offered a tax advantage until 1994; and the increase in the interest rate offered on demand deposits. The fraction of bank bonds $[B B / M]$, increased gradually through 1987, and has remained relatively constant at about $8 \%$ since then. Overall, the holdings of assets within M3 appear to respond to changes in the relative net rates of returns of those assets.

In Greece, only one financial asset outside M3 has been generally available to the public: Treasury bills. For our sample, sales of Treasury bills to the public began in 1985(2), initially with their interest rate set equal to that paid on time deposits: see Figure 9. After 1987, as financial markets were gradually liberalized, a positive spread appeared between the Treasury bill rate and the interest rate on time deposits. ${ }^{7}$ Access to Treasury bills was limited until 1991. The ratio of Treasury bills to M3 (in Figure 11) reflects that, and shows the growing importance of Treasury bills in private portfolios relative to their assets in $\mathrm{M} 3$.

\section{Economic Theory and the Data}

The money demand function (2) is formulated in terms of the levels of interest rates on components of M3 and on Treasury bills. It can be rewritten with a single interest rate and a set of spreads, where this reparameterization may be more interpretable economically. One such reparameterization is:

$$
m^{d}-p=\gamma_{0}+\gamma_{1} y+\delta_{2} R T^{n}+\delta_{3}\left(R B-R T^{n}\right)+\delta_{4}\left(R B-R R^{n}\right)+\gamma_{5} \Delta p,
$$

where $\delta_{2}=\gamma_{2}+\gamma_{3}+\gamma_{4}, \delta_{3}=\gamma_{3}+\gamma_{4}$, and $\delta_{4}=-\gamma_{3}$. The coefficient $\delta_{2}$ captures the total levels effect of the interest rates, and the spreads capture the incremental effects of the own rates relative to the Treasury bill rate. The assumed signs of coefficients in (2) imply that $\delta_{4}<0$. The coefficients $\delta_{2}$ and $\delta_{3}$ are not uniquely signed without additional

\footnotetext{
7 The sale of medium-term Drachma-denominated bonds was resumed in 1986, and their maturity has lengthened in recent years. The administered interest rates on medium-term bonds are linked to the one-year Treasury bill rate, and the spreads of medium-term bond rates over that bill rate have changed little in the last few years.
} 


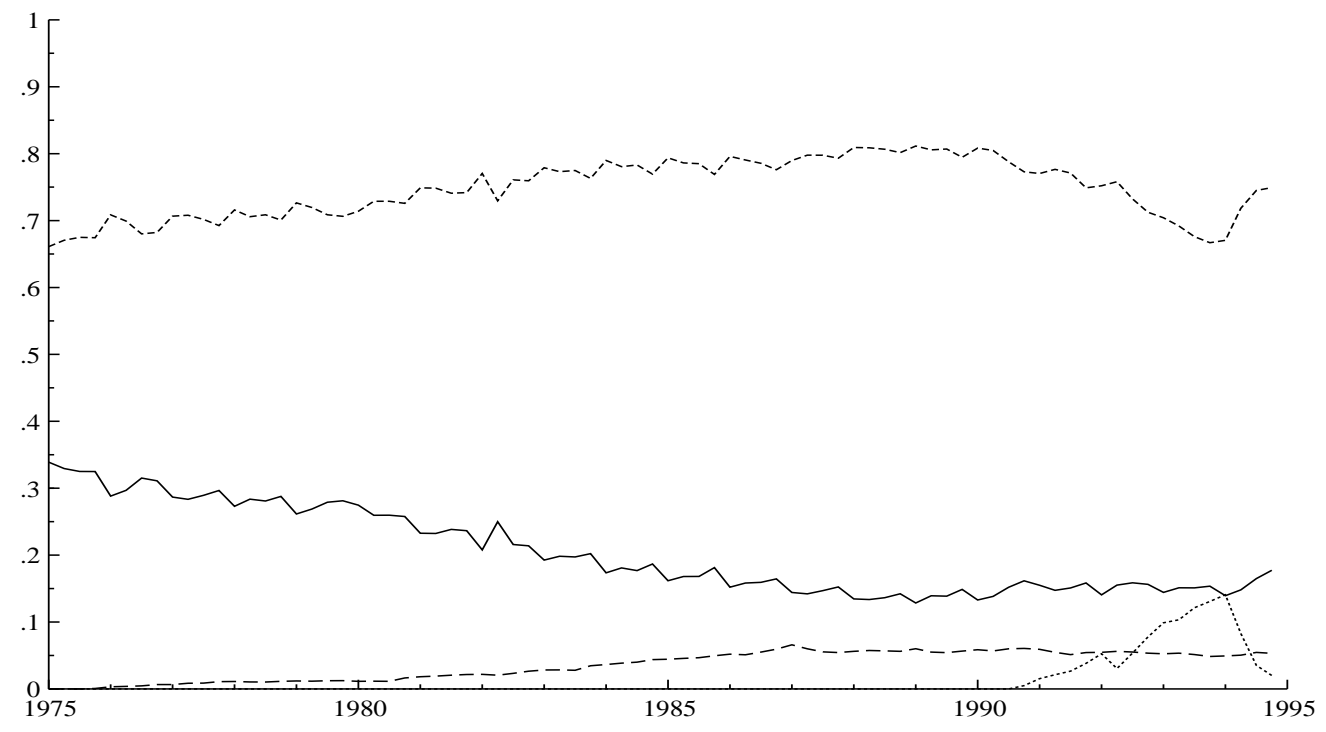

Figure 9: Ratios of various assets to broad money: M1 (-), savings and time deposits $S D+T D(--)$, bank bonds $B B(--)$, and repos $R E P(\cdots)$.

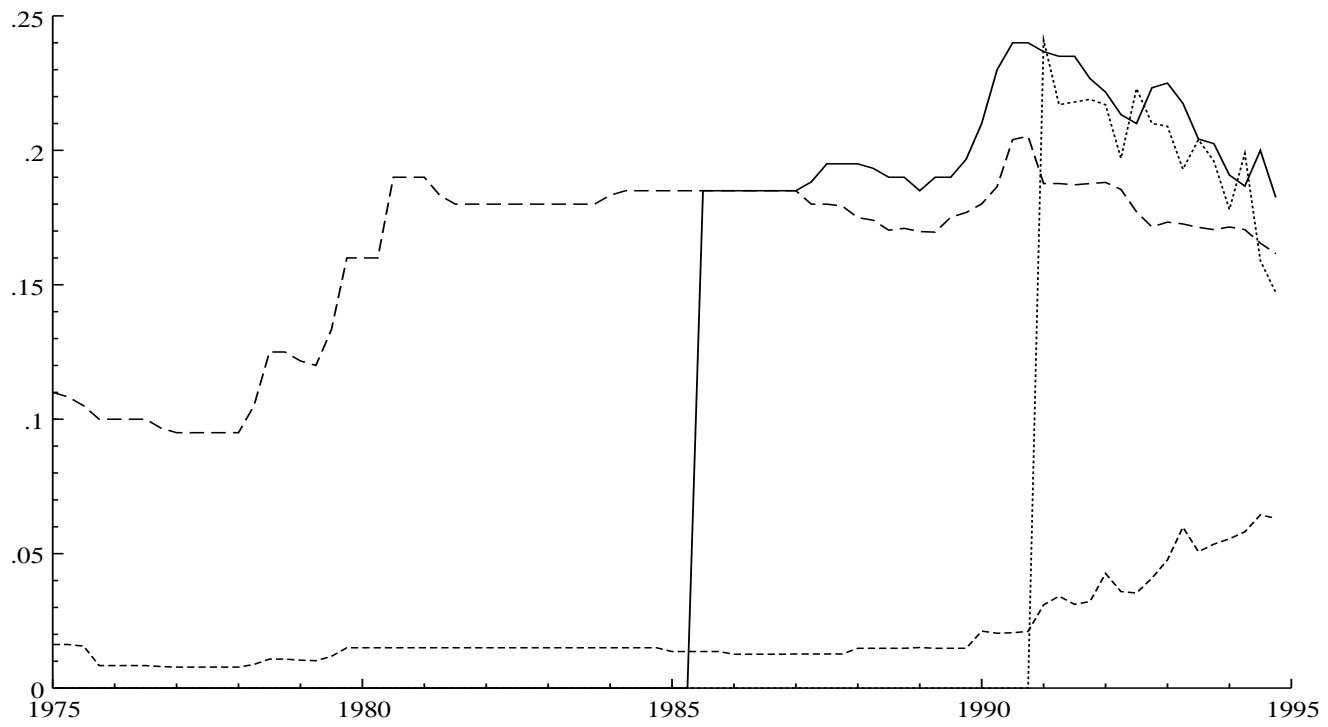

Figure 10: The interest rate on Treasury bills $(R B:-)$, and net interest rates for demand deposits $\left(R D^{n}:---\right)$, time deposits $\left(R T^{n}:--\right)$, and repos $\left(R R^{n}: \cdots\right)$. 


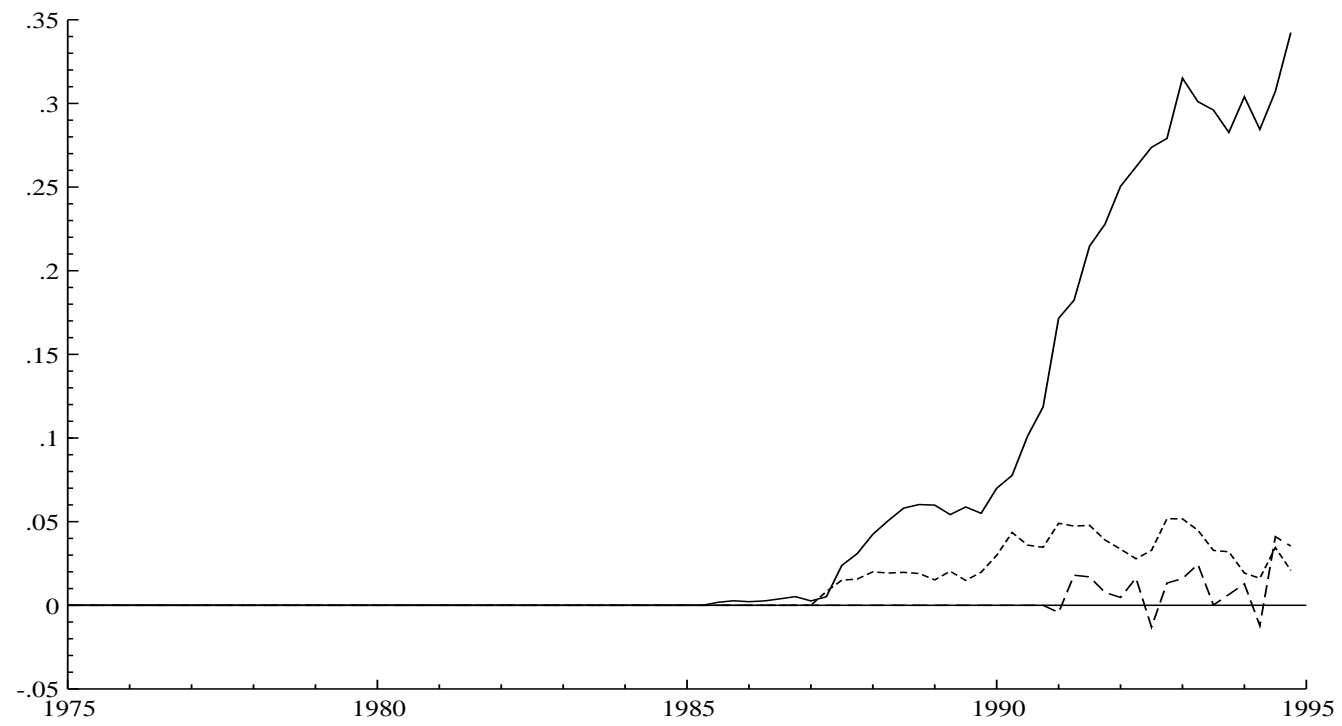

Figure 11: The ratio of outstanding Treasury bills to $\mathrm{M} 3$ (一), and the interest-rate spreads $R B-R T^{n}(--)$ and $R B-R R^{n}(--)$.

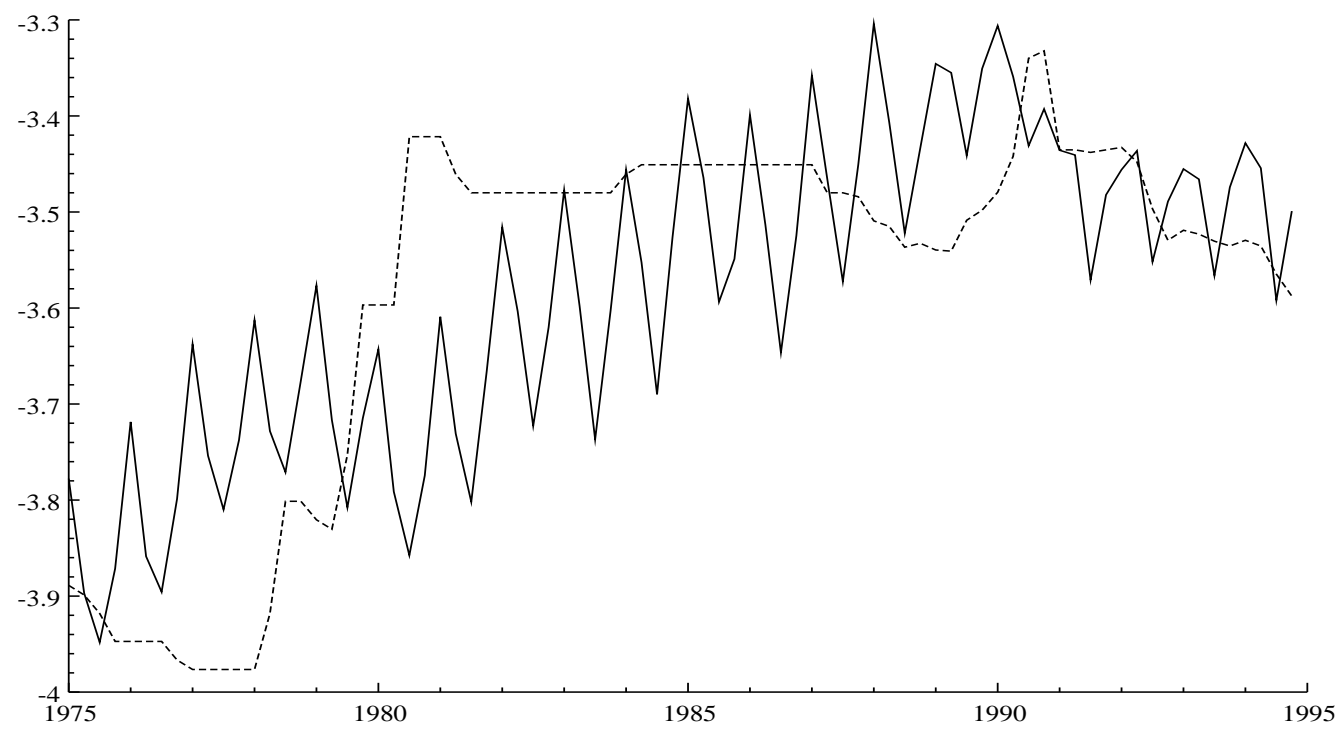

Figure 12: The logarithm of inverse velocity $m-p-y(-)$ and the net interest rate on time deposits $R T^{n}(--)$, plotted with matched means and ranges. 
information. However, it seems likely that $\delta_{2}>0$ and $\delta_{3}<0$, particularly if (for $\delta_{2}$ ) Treasury bills are an imperfect substitute for M3 and if (for $\delta_{3}$ ) the spread $R B-R T^{n}$ is nonzero during some periods when $R B-R R^{n}$ is zero or undefined.

Figure 11 plots the two spreads in $(3),\left(R B-R T^{n}\right)$ and $\left(R B-R R^{n}\right)$. Because the ratio of Treasury bills to M3 is small until 1990, we make the simplifying assumption that Treasury bills only became available to the public as an alternative to M3 beginning in 1991. Thus, in modeling money demand, the spread $\left(R B-R T^{n}\right)$ in (3) is replaced by a modified spread $S T$, which is zero through 1990 and $\left(R B-R T^{n}\right)$ thereafter. Repos are treated similarly, as follows. Because the fraction of repos in M3 was small during the first year that they were available (1991; see Figure 9), we use a modified spread $S R$, defined as zero through 1991 and equal to $\left(R B-R R^{n}\right)$ thereafter. Thus, the empirical money-demand relation is specified as:

$$
m^{d}-p=\gamma_{0}+\gamma_{1} y+\delta_{2} R T^{n}+\delta_{3} S T+\delta_{4} S R+\gamma_{5} \Delta p
$$

Until virtually the end of the sample, the value of outstanding Treasury bills and repos is small relative to $\mathrm{M} 3$, so a simple representation of (4) involves the return on only one financial asset, M3 itself. Figure 12 plots this net return $\left(R T^{n}\right)$ and measured inverse velocity. The latter variable is equivalent to imposing a unit income elasticity in (1) (or $\gamma_{1}=1$ in (4)), and $R T^{n}$ is adjusted in the figure so as to match the mean and range of $(m-p-y)$. While the two series exhibit strong seasonal and dynamic differences, their longer-term movements are similar, suggesting possible cointegration of the two variables. Sections III and IV consider cointegration explicitly.

Foreign-denominated assets represent one additional possible alternative to holding M3. Their return is captured by the rate of depreciation of the exchange rate plus the interest rate on the asset. Figure 13 plots the quarterly depreciation rate $\Delta e$ as well as the domestic inflation rate $\Delta p$, where $E$ is an index of the nominal effective exchange rate using 1988 trade weights $(1970=1.00)$. Notable devaluations occurred in January 1983 (of $15 \frac{1}{2} \%$ ) and October 1985 (of 20\%). In a preliminary analysis, the depreciation rate and foreign interest rates (such as LIBOR) did not appear to matter, except that a dummy (denoted $D E$ ) for 1982(4)-1983(1) helped capture the apparent anticipation and realization of the first major devaluation. Various capital controls were in place for much of the sample, and they may be responsible for the lack of significance of returns on foreign assets. Restrictions on capital movements were significantly liberalized in May 1994, and this allowed the use of new financial instruments like synthetic swaps. Because data for the returns on synthetic swaps are not currently available, we include a dummy (denoted $D S$ ) beginning with their introduction in 1994(3). 


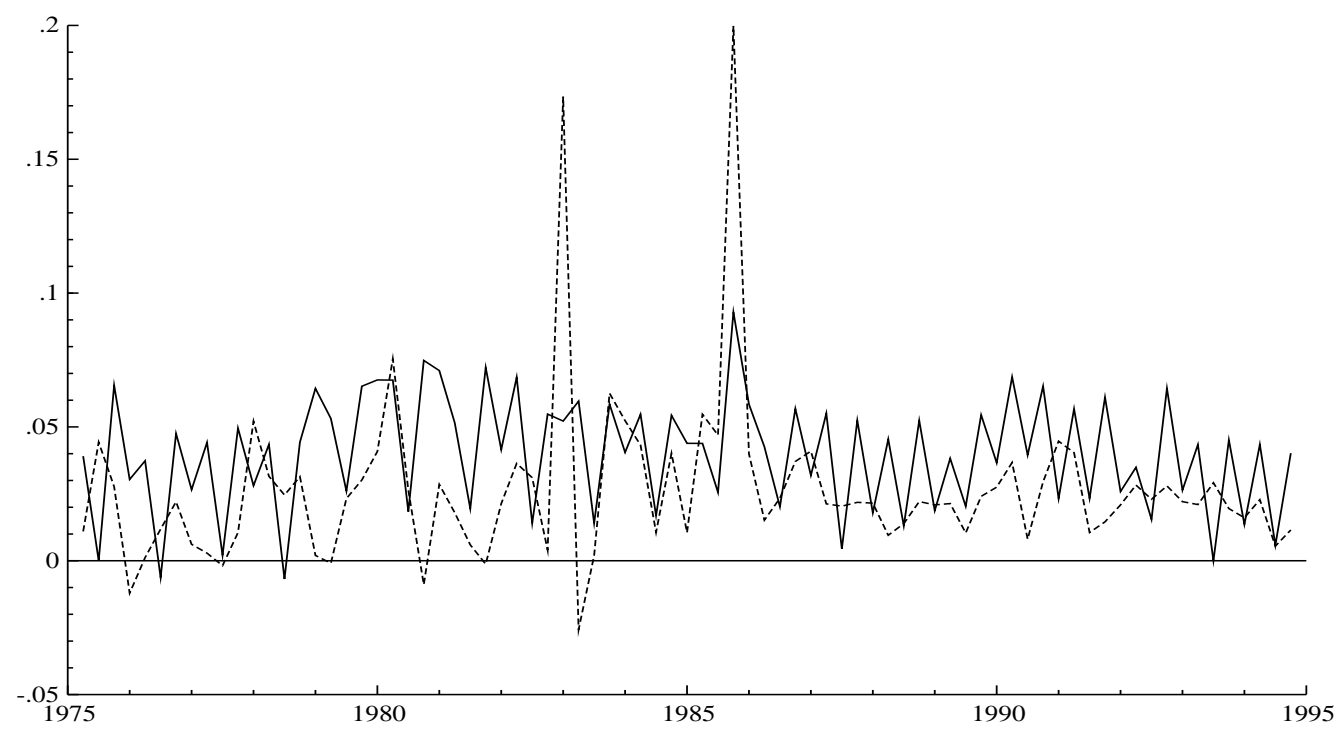

Figure 13: The quarterly inflation rate $\Delta p(-)$ and the quarterly depreciation of the exchange rate $\Delta e(---)$.

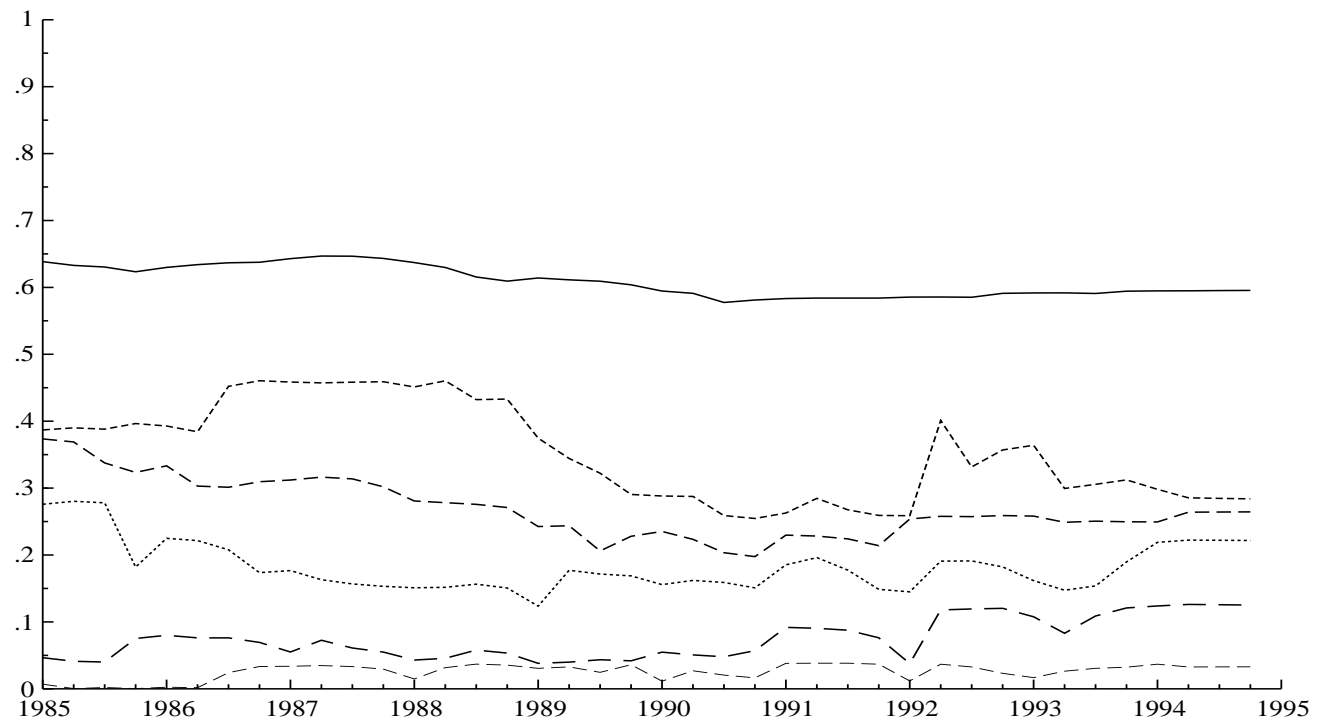

Figure 14: The six recursively estimated eigenvalues. 


\section{Integration and Cointegration}

This section presents unit root tests for the variables of interest (Section III.1). Then, Johansen's $(1988,1991)$ maximum likelihood procedure is applied to test for cointegration among real money, real output, inflation, the interest rate on time deposits, and the spreads between the interest rates on Treasury bills, time deposits, and repos (Section III.2). For further discussion of integration and cointegration, see Engle and Granger (1987), Ericsson (1992), Banerjee, Dolado, Galbraith, and Hendry (1993), Stock (1994), Watson (1994), and Johansen (1995).

\section{Integration}

Before modeling Drachma money demand, it is useful to determine the orders of integration for the variables considered. Table 1 lists the augmented Dickey-Fuller (1981) (ADF) statistics for the central variables in our analysis. The deviation from unity of the estimated largest root is in parentheses, and that deviation should be zero if the series has a unit root. Unit root tests are reported for the original variables (in logs where indicated), for their changes, and for the changes of their changes. This permits testing whether a given series is $\mathrm{I}(0), \mathrm{I}(1), \mathrm{I}(2)$, or $\mathrm{I}(3)$, albeit in a pairwise fashion for adjacent orders of integration. ${ }^{8}$

Empirically, all variables appear to be integrated of order two or lower. Real output, real money, the Treasury bill rate $R B$, and the spreads appear to be $\mathrm{I}(1) .{ }^{9}$ For the other variables, the statistical evidence is less conclusive. From its ADF statistic, $R T$ might be $\mathrm{I}(2)$. However, its estimated second largest root $(0.43=1-0.57$, for a null order of $\mathrm{I}(2))$ is closer to zero than to unity, suggesting that $R T$ is $\mathrm{I}(1)$ in fact. Nominal money and prices might be either I(1) or I(2), so they are transformed to real money and inflation, as in Ericsson, Campos, and Tran (1990) and Johansen (1992b) for U.K. data. Because the univariate tests are known to have low power against some stationary alternatives, multivariate tests of stationarity are calculated below as well.

\section{Cointegration}

Based on these statistical properties of the data and on the economic and historical context discussed in Section II, the current subsection tests for cointegration among the variables $m-p, y, \Delta p, R T^{n}, S T$, and $S R$ in a fourth-order vector autoregression. Table 2 reports the standard statistics and estimates for Johansen's procedure. The maximal eigenvalue and trace eigenvalue statistics $\left(\lambda_{\max }\right.$ and $\left.\lambda_{\text {trace }}\right)$ reject the null of no cointegration in

\footnotetext{
${ }^{8}$ For $i \geq 0$, the notation $\mathrm{I}(i)$ indicates that a variable must be differenced $i$ times to make it stationary. That is, if $x_{t}$ is $\mathrm{I}(i)$, then $\Delta^{i} x_{t}$ is $\mathrm{I}(0)$.

${ }^{9}$ From an economic perspective, a spread might well be $\mathrm{I}(0)$. However, financial innovation may affect the mean of the spread, and that break in mean may well induce apparent empirical nonstationarity in the spread itself.
} 
Table 1.

ADF(4) Statistics for Testing for a Unit Root

\begin{tabular}{|c|c|c|c|c|c|c|c|c|}
\hline \multirow[b]{2}{*}{ Null Order } & \multicolumn{8}{|c|}{ Variable } \\
\hline & $m$ & $p$ & $y$ & $m-p$ & $R T$ & $R B$ & $S T$ & $S R$ \\
\hline $\mathrm{I}(1)$ & $\begin{array}{c}1.25 \\
(0.02)\end{array}$ & $\begin{array}{c}-1.51 \\
(-0.04)\end{array}$ & $\begin{array}{c}-2.54 \\
(-0.34)\end{array}$ & $\begin{array}{c}-1.51 \\
(-0.06)\end{array}$ & $\begin{array}{c}-1.93 \\
(-0.07)\end{array}$ & $\begin{array}{c}-1.74 \\
(-0.11)\end{array}$ & $\begin{array}{c}-1.90 \\
(-0.16)\end{array}$ & $\begin{array}{c}-0.35 \\
(-0.13)\end{array}$ \\
\hline $\mathrm{I}(2)$ & $\begin{array}{c}-3.39^{+} \\
(-0.57)\end{array}$ & $\begin{array}{c}-2.31 \\
(-0.35)\end{array}$ & $\begin{array}{l}-4.13^{* *} \\
(-2.09)\end{array}$ & $\begin{array}{c}-3.87^{*} \\
(-0.74)\end{array}$ & $\begin{array}{c}-2.64 \\
(-0.57)\end{array}$ & $\begin{array}{c}-3.66^{*} \\
(-1.03)\end{array}$ & $\begin{array}{l}-5.22^{* *} \\
(-1.77)\end{array}$ & $\begin{array}{c}-6.49^{* *} \\
(-6.32)\end{array}$ \\
\hline $\mathrm{I}(3)$ & $\begin{array}{l}-5.09^{* *} \\
(-2.15)\end{array}$ & $\begin{array}{l}-4.73^{* *} \\
(-2.49)\end{array}$ & $\begin{array}{l}-8.15^{* *} \\
(-6.35)\end{array}$ & $\begin{array}{l}-4.55^{* *} \\
(-2.14)\end{array}$ & $\begin{array}{l}-4.78^{* *} \\
(-2.64)\end{array}$ & $\begin{array}{l}-6.13^{* *} \\
(-3.43)\end{array}$ & $\begin{array}{l}-7.25^{* *} \\
(-3.82)\end{array}$ & $\begin{array}{c}-3.47^{+} \\
(-5.17)\end{array}$ \\
\hline
\end{tabular}

Notes

1. For a given variable and null order, two values are reported: the fourth-order augmented Dickey-Fuller (1981) statistic, denoted $\mathrm{ADF}(4)$; and (in parentheses) the estimated coefficient on the lagged variable, where that coefficient should be zero under the null hypothesis. A constant term, quarterly dummies, and a trend are included in the corresponding regressions. The maximum available sample is used, and varies across the null order.

2. For any variable $x$ and a null order of $\mathrm{I}(1)$, the $\operatorname{ADF}(4)$ statistic is testing a null hypothesis of a unit root in $x$ against an alternative of a stationary root. For a null order of $\mathrm{I}(2)$ [I(3)], the statistic is testing a null hypothesis of a unit root in $\Delta x\left[\Delta^{2} x\right]$ against an alternative of a stationary root in $\Delta x\left[\Delta^{2} x\right]$.

3. Here and elsewhere in this paper, the superscripts ${ }^{+}, *$, and $* *$ denote rejection at the $10 \%, 5 \%$, and $1 \%$ critical values. The critical values for this table are from MacKinnon (1991). 
Table 2.

A Cointegration Analysis of Greek Money Demand Data

\begin{tabular}{|c|c|c|c|c|c|c|}
\hline Eigenvalues & 0.596 & 0.284 & 0.265 & 0.222 & 0.125 & 0.033 \\
\hline Hypotheses & $r=0$ & $r \leq 1$ & $r \leq 2$ & $r \leq 3$ & $r \leq 4$ & $r \leq 5$ \\
\hline$\lambda_{\max }$ & $46.2^{* *}$ & 17.0 & 15.7 & 12.8 & 6.8 & 1.7 \\
\hline $95 \%$ critical value & 39.4 & 33.5 & 27.1 & 21.0 & 14.1 & 3.8 \\
\hline$\lambda_{\text {trace }}$ & $100.2^{*}$ & 54.0 & 37.0 & 21.3 & 8.5 & 1.7 \\
\hline \multirow[t]{10}{*}{$95 \%$ critical value } & 94.2 & 68.5 & 47.2 & 29.7 & 15.4 & 3.8 \\
\hline & \multicolumn{5}{|c|}{ Standardized eigenvectors $\beta^{\prime}$} & \\
\hline & $m-p$ & $y$ & $\Delta p$ & $R T^{n}$ & $S T$ & $S R$ \\
\hline & 1 & -1.22 & 13.53 & -4.58 & 3.07 & 7.02 \\
\hline & -0.43 & 1 & 0.18 & -0.23 & -7.39 & 15.94 \\
\hline & -0.22 & 0.78 & 1 & -0.73 & -0.48 & -5.66 \\
\hline & 0.50 & -1.95 & -3.31 & 1 & -0.41 & -9.93 \\
\hline & 0.23 & -0.69 & 2.42 & 0.45 & 1 & 0.14 \\
\hline & -0.12 & -0.07 & 0.96 & 0.20 & 0.43 & 1 \\
\hline & \multicolumn{5}{|c|}{ Standardized adjustment coefficients $\alpha$} & \\
\hline$m-p$ & -0.081 & 0.036 & -0.072 & 0.023 & -0.011 & 0.117 \\
\hline$y$ & 0.069 & -0.070 & -0.355 & 0.097 & -0.022 & -0.006 \\
\hline$\Delta p$ & -0.038 & -0.022 & 0.034 & -0.032 & -0.068 & -0.061 \\
\hline$R T^{n}$ & 0.020 & 0.023 & 0.084 & -0.005 & -0.086 & 0.002 \\
\hline$S T$ & -0.001 & 0.009 & 0.048 & 0.040 & 0.057 & -0.016 \\
\hline \multirow[t]{3}{*}{$S R$} & -0.003 & -0.033 & 0.092 & -0.000 & -0.001 & 0.012 \\
\hline & \multicolumn{6}{|c|}{ Weak exogeneity test statistics } \\
\hline & $m-p$ & $y$ & $\Delta p$ & $R T^{n}$ & $S T$ & $S R$ \\
\hline \multirow[t]{3}{*}{$\chi^{2}(1)$} & $3.89^{*}$ & 1.92 & 2.20 & 1.62 & 0.01 & 0.06 \\
\hline & \multicolumn{6}{|c|}{ Statistics for testing the significance of a given variable } \\
\hline & $m-p$ & $y$ & $\Delta p$ & $R T^{n}$ & $S T$ & $S R$ \\
\hline \multirow[t]{3}{*}{$\chi^{2}(1)$} & $26.4^{* *}$ & $7.4^{* *}$ & $41.7^{* *}$ & $37.8^{* *}$ & $7.9^{* *}$ & $4.7^{*}$ \\
\hline & \multicolumn{6}{|c|}{ Multivariate statistics for testing stationarity } \\
\hline & $m-p$ & $y$ & $\Delta p$ & $R T^{n}$ & $S T$ & $S R$ \\
\hline$\chi^{2}(5)$ & $63.8^{* *}$ & $60.4^{* *}$ & $54.9^{* *}$ & $54.6^{* *}$ & $49.7^{* *}$ & $48.7^{* *}$ \\
\hline
\end{tabular}

Notes

1. The vector autoregression includes four lags on each variable $\left(m-p, y, \Delta p, R T^{n}, S T, S R\right)$, a constant term, centered seasonal dummies $\left(Q_{t-1}, Q_{t-2}, Q_{t-3}\right)$, the devaluation dummy $D E_{t}$, the subsample seasonal dummies $\left(D_{89 t} \cdot Q_{t}, D_{89 t} \cdot Q_{t-1}, D_{89 t} \cdot Q_{t-2}, D_{89 t} \cdot Q_{t-3}\right)$, and the dummy for synthetic swaps $D S_{t}$. The estimation period is 1976(2)-1994(4).

2. The statistics $\lambda_{\max }$ and $\lambda_{\text {trace }}$ are Johansen's maximal eigenvalue and trace eigenvalue statistics for testing cointegration, adjusted for degrees-of-freedom. The null hypothesis is in terms of the cointegration rank $r$ and, e.g., rejection of $r=0$ is evidence in favor of at least one cointegrating vector. The critical values are taken from Osterwald-Lenum (1992, Table 1).

3. The weak exogeneity [significance; multivariate stationarity] test statistics are evaluated under the assumption that $r=1$ and so are asymptotically distributed as $\chi^{2}(1)\left[\chi^{2}(1) ; \chi^{2}(5)\right]$ if weak exogeneity [no long-run presence; stationarity] of the specified variable is valid. 
favor of one cointegrating relationship at the $1 \%$ and $5 \%$ levels respectively. Figure 14 plots the six (recursively estimated) eigenvalues, which are the basis for the maximum likelihood test statistics. ${ }^{10}$ The eigenvalues are reasonably constant over time; and the largest eigenvalue is always substantially larger than the remaining five, implying that the finding of just one cointegrating vector is robust to the choice of sample. This subsection tests various hypotheses about the long-run and feedback coefficients, tests for the stationarity of individual variables in a multivariate setting, and compares the Johansen and Engle-Granger estimates of the cointegrating vector.

Table 2 also reports the standardized eigenvectors and adjustment coefficients, denoted $\beta^{\prime}$ and $\alpha$ in a frequently used notation. The first row of $\beta^{\prime}$ is the estimated cointegrating vector, which can be written in the form of (4):

$$
m-p=\hat{\gamma}_{0}+1.22 y+4.58 R T^{n}-3.07 S T-7.02 S R-3.38(4 \cdot \Delta p),
$$

where a circumflex ^ denotes the corresponding estimate. Each coefficient has its anticipated sign and is statistically significantly different from zero. The restriction of unit income homogeneity is not rejected. The associated likelihood-ratio statistic is $\chi^{2}(1)=0.57[0.45]$, where " $\chi^{2}(1)$ " specifies the asymptotic distribution under the null hypothesis, " 0.57 " is the observed value of the statistic, and the asymptotic $p$-value is in brackets. ${ }^{11}$ See Johansen and Juselius (1990) for the form of the test. Also, the coefficients on the spreads can be imposed to be equal: $\chi^{2}(1)=1.16$ [0.28]. With that restriction, (5) can be reparameterized with a single spread, that of the Treasury bill rate relative to the average of the interest rates on time deposits and repos. Inflation (measured as an annual rate) has a semi-elasticity of over 3. While apparently high, this elasticity is similar to those obtained in studies of broad money demand for other countries. For instance, Taylor's (1986) error correction models of M2 demand for the Netherlands, Germany, and France imply elasticities of $-0.91,-2.67$, and -0.42 for annual inflation. However, while elasticities may be similar, the implications for actual money demand differ because the paths of interest rates and inflation are not the same across countries.

Equation (5) may be expressed explicitly in terms of the interest rates $R T^{n}, R R^{n}$, and $R B$ :

$$
m-p=\hat{\gamma}_{0}+1.22 y+7.65 R T^{n}+7.02 R R^{n}-10.09 R B-3.38(4 \cdot \Delta p) .
$$

10 To permit recursive estimation, the subsample seasonal dummies $D_{89 t} \cdot Q_{t-i}$, the spreads $S T_{t}$ and $S R_{t}$, and $D E_{t}$ are perturbed slightly (by 0.0001) in various periods early in the sample. The recursive eigenvalues are calculated, conditional on full-sample estimates of the lagged dynamics.

11 Equally, long-run unit price and income homogeneity are not rejected in a fourth-order vector autoregression of $m, p, y, R T^{n}, S T$, and $S R$. 
The semi-elasticities of the own rates are approximately the magnitude of and opposite in sign to the rate on Treasury bills, although statistically these restrictions are rejected: $\chi^{2}(2)=11.16$ [0.004]. For comparison with another money demand equation, Hendry and Ericsson (1991a) obtain a semi-elasticity of -7.0 on the outside interest rate for M2 in the United Kingdom, so the magnitude of the semi-elasticities in (6) seems reasonable.

The coefficients in the first column of $\alpha$ in Table 2 measure the feedback effects of the (lagged) disequilibrium in the cointegrating relation onto the variables in the vector autoregression. In particular, -0.081 is the estimated feedback coefficient for the money equation. The negative coefficient implies that lagged excess money induces smaller holdings of current money. Its numerical value implies slow adjustment to remaining disequilibrium - approximately $8 \%$ in the first quarter. Numerically, the estimated coefficient lies at the lower end for developed and developing countries: $-0.26,-0.15$, and -0.20 for the Netherlands, Germany, and France (all M2), and approximately -0.12 for Argentina (M3); see Taylor (1986) and Kamin and Ericsson (1993). The lower adjustment coefficient for Greece may reflect the lack of availability of alternative assets to M3 and a generally repressed financial system. Still, the adjustment coefficient is similar to that found by Hendry and Ericsson (1991b) for narrow money demand in the United Kingdom ( -0.093$)$, indicating that some differences across countries and across aggregates can be expected.

The next row in Table 2 reports values of the statistic for testing weak exogeneity of a given variable for the cointegrating vector. That is, the statistic tests whether or not a row in $\alpha$ is zero; see Johansen (1992a, 1992b). If a given row is zero, disequilibrium in the cointegrating relationship does not feed back directly onto the corresponding variable. The tests show that output, inflation, the interest rate on Treasury bills, and the spreads are (individually) weakly exogenous for real money demand. A joint test of their weak exogeneity is also statistically acceptable, as is the joint test of their weak exogeneity plus long-run unit income elasticity and equality of the spreads' coefficients: $\chi^{2}(5)=8.70$ $[0.122]$ and $\chi^{2}(7)=9.78[0.20]$ respectively. With all seven restrictions imposed on the vector autoregression, the estimate of the cointegrating vector is:

$$
m-p=\hat{\gamma}_{0}+1.00 y+5.08 R T^{n}-4.00 S T-4.00 S R-3.76(4 \cdot \Delta p)
$$

with a solution in the levels of the interest rates being:

$$
m-p=\hat{\gamma}_{0}+1.00 y+9.08 R T^{n}+4.00 R R^{n}-8.00 R B-3.76(4 \cdot \Delta p) .
$$

The restricted feedback coefficient is -0.140 . All the coefficients in (8) satisfy the economic-theoretic restrictions postulated for (2) and (4). The long-run income elasticity 
is unity, coefficients on the own rates are positive, those on the outside rate and inflation are negative, and those on the spreads (in (7)) are negative.

Valid weak exogeneity permits analysis of the cointegrating vector in a singleequation conditional error correction model of money without loss of information, so Section IV turns to single equation modeling. The remainder of the current section considers significance tests of the variables in the cointegrating vector and multivariate tests of unit roots, and it compares the cointegration results in Table 2 with those from the Engle-Granger procedure.

The penultimate row of Table 2 reports chi-squared statistics for testing the significance of individual variables in the cointegrating vector. Each variable is significant at the $5 \%$ level, and all but one $(S R)$ are significant at the $1 \%$ level.

The final row of Table 2 reports values of a multivariate statistic for testing the stationarity of a given variable. This statistic tests the restriction that the cointegrating vector contains all zeros except for a unity corresponding to the designated variable, where the test is conditional on there being one cointegrating vector. For instance, the null hypothesis of stationary real money implies that the cointegrating vector is $\left(\begin{array}{llllll}1 & 0 & 0 & 0 & 0 & 0\end{array}\right)^{\prime}$. Empirically, all the tests reject stationarity with $p$-values of less than $0.01 \%$. By being multivariate and so involving a larger information set, these statistics may have higher power than their univariate counterparts in Table 1. Also, the null hypothesis is the stationarity of a given variable rather than the nonstationarity thereof, and that may be more appealing. That said, these rejections of stationarity are in line with the inability in Table 1 to reject the null hypothesis of a unit root in each of these variables.

Engle and Granger's (1987) procedure is another popular approach for testing cointegration and for estimating the cointegrating vector. The Johansen and Engle-Granger procedures embody different assumptions about dynamics, so it is useful to compare results from both techniques. In the Engle-Granger procedure, the long-run relationship in (2) is estimated without regard to short-term dynamics, and the residuals from this regression are tested for stationarity. If the residuals are stationary, then (2) represents a cointegrating relationship.

This procedure, though simple, may have poor finite-sample properties because it generally does not use all available information on dynamics efficiently; see Banerjee, Dolado, Hendry, and Smith (1986) and Kremers, Ericsson, and Dolado (1992). For comparison with (5) and (7) [and (10) and (14) below], the static regression for the Engle-Granger procedure is: 


$$
\begin{aligned}
& m-p=\hat{\gamma}_{0}+2.25 y+0.28 R T^{n}-3.46 S T+1.17 S R-0.44(4 \cdot \Delta p) \\
& T=74[1976(3)-1994(4)] \quad R^{2}=0.945 \quad \hat{\sigma}=5.79 \% \quad d w=0.87 \\
& A D F(4)=-2.50 \quad A D F(0)=-4.46 .
\end{aligned}
$$

$T, R^{2}, \hat{\sigma}$, and $d w$ are the sample size of the estimation period, the squared multiple correlation coefficient, the estimated equation standard error, and the Durbin-Watson statistic respectively; and the coefficients are estimated by least squares. The ADF statistics are calculated with a constant and trend on the residuals from the static regression (9), which itself includes both types of seasonal dummies and the dummies $D E$ and $D S$. Neither ADF statistic is significant at MacKinnon's (1991) 90\% critical level. Even if cointegration is assumed, the coefficient on $y$ is twice that suggested by the quantity theory, and the coefficient on $\Delta p$ is very small economically. These discrepancies between the Johansen and Engle-Granger procedures may arise because the latter procedure imposes a "common factor restriction" on the dynamics. For the Greek data, this restriction is rejected at any reasonable significance level: $F(44,36) \approx 4.37$ [0.0000]; and the ECM in (12) below provides additional evidence against this restriction being valid. Banerjee, Dolado, Hendry, and Smith (1986) show that the static estimates of the cointegrating vector have large finite-sample biases for low values of $R^{2}$. In (9), even 0.945 may be "low," noting that under cointegration $R^{2}$ tends to unity as the sample size increases.

\section{An Error Correction Model of Money Demand}

In light of the results on cointegration and weak exogeneity using Johansen's procedure, this section develops a parsimonious, conditional, single-equation model for money demand. Such a model is of interest for several reasons. A conditional money-demand model may be constant, even when the reduced form vector autoregression for Johansen's procedure is nonconstant. As Judd and Scadding (1982) emphasize, constancy is particularly important for money demand equations. The graphs of the Greek data indicate changes in seasonal patterns for some variables, high variability of the inflation rate, and marked changes in the interest rates as financial markets were liberalized, suggesting the possibility of large structural breaks. Also, as a practical matter, a well-specified, parsimonious model may be easier to obtain in a single-equation context than in a multipleequation one. Section IV.1 develops the parsimonious ECM from a general autoregressive distributed lag; Section IV.2 evaluates that ECM's short- and long-run properties; and Section IV.3 examines its statistical properties, including parameter constancy.

\section{General to Specific Modeling}

Given the choice of variables and the lag length in the vector autoregression above, a fourth-order autoregressive distributed lag (ADL) in $m, p, y, R T^{n}, S T$, and $S R$ is a 
natural starting point for single-equation modeling. Paralleling the vector autoregression, this model was extended in three ways. First, the dummy variable $D E$ for 1982(4)1983(1) was included to account for fluctuations in money demand associated with the $15 \frac{1}{2}$ percent devaluation of the Drachma in early January 1983. Second, the dummy variable $D S$ was included to proxy for the returns on synthetic swaps. Third, four seasonal dummies beginning in 1989 were included so as to allow for the change in seasonality of measured GDP. This subsection estimates that autoregressive distributed lag, solves for its long-run properties, reinterprets it as an unrestricted ECM, and reduces it to a parsimonious ECM.

The long-run static solution to the estimated autoregressive distributed lag is:

$$
\begin{aligned}
& m=\underset{(5.69)}{4.31}+\underset{(0.11)}{1.01} p+\underset{(0.52)}{1.04} y+\underset{(2.59)}{4.56} R T^{n}-\underset{(1.29)}{3.87} S T-\underset{(5.22)}{7.05} S R . \\
& T=75[1976(2)-1994(4)] .
\end{aligned}
$$

The coefficients on $p$ and $y$ are numerically close to unity, and each is much less than a standard deviation away from unity, so the long-run solution to the ADL could likely be formulated in terms of the inverse velocity. Additionally, the coefficients on $R T^{n}, S T$, and $S R$ are similar to the system estimates in (5), providing further (indirect) evidence of the validity of weak exogeneity.

Autoregressive distributed lags have error correction representations. Thus, the longrun money demand relation (2) can be explicitly embedded in the ADL model, written as an ECM:

$$
\begin{aligned}
\Delta m_{t}= & \sum_{i=1}^{k} \theta_{1 i} \Delta m_{t-i}+\sum_{i=0}^{k} \theta_{2 i} \Delta p_{t-i}+\sum_{i=0}^{k} \theta_{3 i} \Delta y_{t-i} \\
& +\sum_{i=0}^{k} \theta_{4 i} \Delta R T_{t-i}^{n}+\sum_{i=0}^{k} \theta_{5 i} \Delta S T_{t-i}+\sum_{i=0}^{k} \theta_{6 i} \Delta S R_{t-i} \\
& +\theta_{7}\left(m-m^{*}\right)_{t-1}+\sum_{i=0}^{3}\left(\theta_{8 i} Q_{t-i}+\theta_{9 i} D_{89 t} Q_{t-i}\right)+\theta_{0}^{\prime} D_{t}+\varepsilon_{t}
\end{aligned}
$$

The lag length $k$ is 3 ; coefficients are denoted by $\theta_{j}$ (or $\theta_{j i}$ if lags are involved); $m^{*}$ is the desired nominal money stock obtained from (2); $\left\{Q_{t-i}\right\}$ are centered seasonal dummies, except that $Q_{t}$ is the constant term; $D_{89 t}$ is a step dummy, being zero through 1988 and unity from 1989(1) onwards; $D_{t}$ is the vector $(D E, D S)_{t}^{\prime}$; and $\varepsilon_{t}$ is the equation's error. The model has a flexible lag structure, yet yields the static equilibrium (2) when growth rates (including $\Delta p)$ are set to zero. The "error correction" term $\left(m-m^{*}\right)_{t-1}$ 
corresponds to the disequilibrium from the long-run solution, with money adjusting in subsequent periods if $\theta_{7}<0$.

The ECM generalizes the traditional partial adjustment model, allowing for different speeds of reaction to the different determinants of money demand, yet through the error correction term ensures that the long-run relationship holds in steady state. The specification in (11) is also related to a theory of "inventory adjustment," in which shortrun factors determine fluctuations of money holdings within given bands, while long-run factors influence the level of the bands themselves. See Miller and Orr (1966), Akerlof (1979), Akerlof and Milbourne (1980), Milbourne (1983), and Smith (1986). Equally, the ECM is a re-parameterization of a general autoregressive distributed-lag model in $(\log )$ levels. The ECM formulation is attractive in that it immediately provides the parameter describing the rate of short-run adjustment to disequilibrium. See de Brouwer and Ericsson (1995) for an extended expository discussion of the relationship between autoregressive distributed lags, ECMs, and their long-run solutions.

Table 3 lists the estimated coefficients, standard errors, and test statistics for the ECM representation in (11), which is our starting point for the general-to-specific modeling of Greek money demand. The coefficient on the error correction term $(m-p-y)_{t-1}$ is -0.127 , close to that obtained by Johansen's procedure. Likewise, the estimated coefficients on $p_{t-1}$ and $y_{t-1}$ are close to zero, both numerically and statistically, implying that the hypothesis of long-run unit price and income homogeneity imbedded in $(m-p-y)_{t-1}$ is reasonable. Formally, the restriction of long-run price and income homogeneity is not rejected $\left(L M_{h}\right)$.

Table 3 and the regressions below include diagnostic statistics for testing against various alternative hypotheses: residual autocorrelation $(d w$ and $A R)$, skewness and excess kurtosis (Normality), autoregressive conditional heteroscedasticity ( $A R C H$ ), RESET (RESET), heteroscedasticity (Hetero), heteroscedasticity quadratic in the regressors (alternatively, functional form mis-specification) (Form), non-innovation errors relative to a more general model (Inn), and predictive failure (Chow, Chow's prediction interval statistic). ${ }^{12}$ The null distribution is designated by $\chi^{2}(\cdot)$ or $F(\cdot, \cdot)$, the degrees of freedom fill the parentheses, and (for $A R$ and $A R C H$ ) the lag order is the first degree of freedom. Statistically, the ADL appears reasonably well specified, with the exception of some autocorrelation that is possibly due to the considerable over-parameterization of the unrestricted ADL.

The unrestricted ADL is valuable for obtaining the long-run solution (10), but it

12 For references on the test statistics, see Durbin and Watson (1950, 1951), Box and Pierce (1970), Godfrey (1978), and Harvey (1981, p. 173); Jarque and Bera (1980) and Doornik and Hansen (1994); Engle (1982); Ramsey (1969); White (1980, p. 825) and Nicholls and Pagan (1983) (the latter two on both Hetero and Form); and Chow (1960). The PcGive manual, Doornik and Hendry (1994), also provides extensive discussions of these statistics. 
Table 3.

The Unrestricted Error Correction Representation for Broad Money Conditional on Prices, Real Output, and Interest Rates

\begin{tabular}{|c|c|c|c|c|}
\hline \multirow{2}{*}{ Variable } & \multicolumn{4}{|c|}{ Lag $i$} \\
\hline & 0 & 1 & 2 & 3 \\
\hline$\Delta m_{t-i}$ & $\begin{array}{l}-1.0 \\
(-)\end{array}$ & $\begin{array}{c}-0.262 \\
(0.140)\end{array}$ & $\begin{array}{c}0.586 \\
(0.114)\end{array}$ & $\begin{array}{c}0.300 \\
(0.137)\end{array}$ \\
\hline$\Delta p_{t-i}$ & $\begin{array}{c}-0.485 \\
(0.132)\end{array}$ & $\begin{array}{c}-0.592 \\
(0.146)\end{array}$ & $\begin{array}{c}-0.180 \\
(0.128)\end{array}$ & $\begin{array}{c}-0.094 \\
(0.126)\end{array}$ \\
\hline$\Delta y_{t-i}$ & $\begin{array}{c}0.007 \\
(0.078)\end{array}$ & $\begin{array}{c}0.118 \\
(0.087)\end{array}$ & $\begin{array}{r}-0.030 \\
(0.077)\end{array}$ & $\begin{array}{c}0.003 \\
(0.064)\end{array}$ \\
\hline$\Delta R T_{t-i}^{n}$ & $\begin{array}{c}-0.164 \\
(0.272)\end{array}$ & $\begin{array}{c}0.228 \\
(0.266)\end{array}$ & $\begin{array}{c}-0.038 \\
(0.248)\end{array}$ & $\begin{array}{c}0.300 \\
(0.240)\end{array}$ \\
\hline$\Delta S T_{t-i}$ & $\begin{array}{l}-0.451 \\
(0.287)\end{array}$ & $\begin{array}{c}-0.156 \\
(0.292)\end{array}$ & $\begin{array}{c}0.737 \\
(0.259)\end{array}$ & $\begin{array}{c}0.625 \\
(0.241)\end{array}$ \\
\hline$\Delta S R_{t-i}$ & $\begin{array}{l}1.044 \\
(0.659)\end{array}$ & $\begin{array}{l}1.153 \\
(0.571)\end{array}$ & $\begin{array}{l}1.298 \\
(0.491)\end{array}$ & $\begin{array}{c}0.485 \\
(0.360)\end{array}$ \\
\hline$(m-p-y)_{t-i}$ & & $\begin{array}{r}-0.127 \\
(0.049)\end{array}$ & & \\
\hline$p_{t-i}$ & & $\begin{array}{c}0.001 \\
(0.014)\end{array}$ & & \\
\hline$y_{t-i}$ & & $\begin{array}{c}0.006 \\
(0.067)\end{array}$ & & \\
\hline$R T_{t}^{n}, S_{t}, S R_{t}$ & $\begin{array}{c}0.581 \\
(0.163)\end{array}$ & $\begin{array}{r}-0.987 \\
(0.477)\end{array}$ & $\begin{array}{r}-0.404 \\
(0.790)\end{array}$ & \\
\hline$Q_{t-i}$ & $\begin{array}{c}-0.549 \\
(0.814)\end{array}$ & $\begin{array}{c}-0.057 \\
(0.029)\end{array}$ & $\begin{array}{r}-0.006 \\
(0.030)\end{array}$ & $\begin{array}{c}-0.024 \\
(0.033)\end{array}$ \\
\hline$D E_{t}, D S_{t}$ & $\begin{array}{c}-0.033 \\
(0.007)\end{array}$ & $\begin{array}{c}-0.023 \\
(0.015)\end{array}$ & & \\
\hline$D_{89 t} \cdot Q_{t-i}$ & $\begin{array}{c}0.006 \\
(0.005)\end{array}$ & $\begin{array}{c}0.002 \\
(0.016)\end{array}$ & $\begin{array}{c}-0.031 \\
(0.016)\end{array}$ & $\begin{array}{c}-0.001 \\
(0.016)\end{array}$ \\
\hline $\begin{array}{l}T=75[1976(2) \\
d w=2.39 L M \\
A R: F(5,31)= \\
\text { Normality }: \chi^{2}(2\end{array}$ & $\begin{array}{l}1994(4)] \\
: F(2,36 \\
94^{*} \quad A I \\
=1.26\end{array}$ & $\begin{array}{l}\quad R^{2}=0 \\
=0.01 \\
R C H: F( \\
R E S E T\end{array}$ & $\begin{array}{l}.9845 \\
4,28)= \\
\Gamma: F(1,3\end{array}$ & $\begin{array}{l}\hat{\sigma}=0.7776 \% \\
0.78 \\
\hat{y}=3.37\end{array}$ \\
\hline
\end{tabular}

Notes

1. The dependent variable is $\Delta m_{t}$. Even so, the equation is in levels, not in differences, noting the error correction term.

2. The variables $\left\{Q_{t-i}\right\}$ are the centered seasonal dummies, except that $Q_{t}$ is the constant term. 
has far too many parameters for many other uses. While no rules guarantee obtaining a successful parsimonious model from the ADL, some intuitive guidelines seemed helpful in simplification. First, the variables $m, p, y, R T^{n}, S T$, and $S R$ were transformed to current and lagged differences and one (possibly lagged) level, as in Table 3. In addition, $m_{t-1}, p_{t-1}$, and $y_{t-1}$ were transformed to the differential $(m-p-y)_{t-1}$ and the two log-levels, $p_{t-1}$ and $y_{t-1}$, thereby reparameterizing these variables as the error correction term and two possibly redundant lags. Combined, the two types of transformations helped obtain a relatively orthogonal set of regressors, making interpretation and simplification easier. Second, shorter lag lengths were preferred to longer ones. Third, because of their economic importance, variables directly involved in the long-run solution were not deleted. See Ericsson, Campos, and Tran (1990), Hendry and Ericsson (1991a, 1991b), and Hendry (1995) for more discussion on reparameterizations and general-to-specific modeling.

Having applied the transformations above and following these informal guidelines, the model in Table 3 could be simplified to the following parsimonious, economically interpretable, and statistically acceptable ECM. Appendix II describes the simplification path in greater detail.

$$
\begin{aligned}
& \Delta m_{t}=-\begin{array}{ccc}
0.117 & 0.071) \\
(0.071) & 0.671 \Delta m_{t-1} \Delta m_{t-2} & -0.394 \Delta \Delta_{2} p_{t} \\
{[0.078]} & 0.075) & (0.059) \\
0.095] & {[0.066]}
\end{array}
\end{aligned}
$$

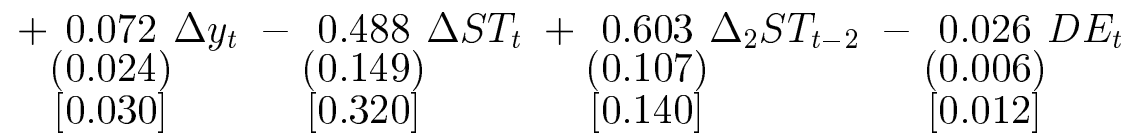

$$
\begin{aligned}
& \begin{array}{ccc}
-0.086 & (m-p-y)_{t-1}+0.410 R T_{t}^{n}-0.675 S_{t} \\
(0.011) & (0.053) & (0.140) \\
{[0.013]} & 0.061] & {[0.171]}
\end{array}
\end{aligned}
$$

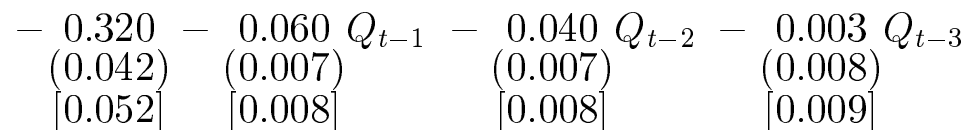

$$
\begin{aligned}
& T=75[1976(2)-1994(4)] \quad R^{2}=0.9712 \quad \hat{\sigma}=0.8128 \% \quad D W=2.30 \\
& A R(5,56)=2.04 \quad A R C H: F(4,53)=0.57 \\
& \text { Normality }: \chi^{2}(2)=0.85 \quad R E S E T: F(1,60)=0.71 \\
& \text { Hetero }: F(22,38)=0.44 \quad \text { Inn }: F(25,36)=1.23 \text {. }
\end{aligned}
$$

Ordinary equation standard errors appear in parentheses $(\cdot)$; White (1980) and MacKinnon and White's (1985) heteroscedasticity consistent standard errors appear in square brackets [.]; and $S$ is $(S T+S R) / 2$, the average of the two spreads, and so is also $R B-\left(R T^{n}+R R^{n}\right) / 2$. Without loss of generality, (12) can be written in a form similar to (11) but with $\Delta(m-p)_{t}$ as the dependent variable, in which case the error correction term is: 


$$
-0.086\left[m-p-y-4.77 R T^{n}+7.85 S+3.59(4 \cdot \Delta p)\right]_{t-1}
$$

see Hendry and Ericsson (1991b, equation (15)).

\section{Short- and Long-run Properties of the Model}

Both short- and long-run properties can be derived from (12). The coefficient on the error correction term is highly significant statistically, establishing that a long-run (cointegrating) relationship exists between broad money, prices, real output, the net interest rate on time deposits, and the spreads. The size of this coefficient suggests that the adjustment to disequilibria via the error correction term is slow. The mean lags for $p, y, R T^{n}, S T$, and $S R$ are 19,5,5,8, and 5 quarters respectively; their median lags are all somewhat shorter, being $12,5,4,7$, and 4 quarters respectively. ${ }^{13}$ In (12), current inflation has a negative and numerically small coefficient, implying that in essence the ECM is modeling $\Delta m_{t}$ in the short run, although real money (and velocity) is being determined in the long run through the error correction term. Such a relationship is consistent with $S s$-type models of money demand, in which short-run factors determine movements in nominal money given desired bands, and longer-run factors (including the price level) determine the bands themselves.

The solved static long-run money demand function from (12) is:

$$
(m-p)^{s}=-3.72+y+4.77 R T^{n}-7.85 S
$$

This long-run relationship between inverse velocity and (for the most part) $R T^{n}$ is visually apparent in Figure 12 above, noting that $S=0$ until 1991. Long-run unit elasticities for prices and output are not rejected; and the estimated semi-elasticity of the nominal (net) interest rate on time deposits is 4.77 , implying an elasticity of about 0.7 when annual interest rates are 15 percent.

Other steady-state solutions also can be derived. For example, if money and prices are assumed to grow at the same rate $(\Delta m=\Delta p \equiv g)$, the dynamic steady-state solution is:

$$
(m-p)^{d}=-3.72+y+4.77 R T^{n}-7.85 S-3.59(4 g)
$$

13 For computational convenience, the mean and median lags were calculated by estimating equation (12) without imposing long-run unit income and price elasticities, long-run equality of elasticities for $S T$ and $S R$, equal coefficients on $\Delta p_{t}$ and $\Delta p_{t-1}$, and equal coefficients with opposite sign for $S T_{t-2}$ and $S T_{t-4}$. Because these restrictions are empirically acceptable and the corresponding coefficients are precisely estimated, the derived mean and median lags from the less restricted equation should not differ much from those for (12). 
where $4 g$ is the annualized nominal growth rate. From (15), inverse velocity in such a steady state depends negatively on the inflation rate, positively on the own rate of return, and negatively on the defined spread. Given the limited range of financial assets available and the underdeveloped nature of the capital market, real assets have been and are an important component of an investor's portfolio. To the extent that the rate of inflation reflects the rate of return on real assets, it is an important determinant of the demand for money.

Equations (5), (7), (10), and (14) (equally, (15)) present estimates of the long-run money demand relation under somewhat different assumptions. Equations (7), (10), and (14) assume weak exogeneity, with (14) also relying on a valid simplification from Table 3. Equation (5) does not assume weak exogeneity, but its estimates may be more sensitive than (10) and (14) to mis-specification in the equations for income, inflation, and the interest rates. That said, all four estimated long-run solutions are remarkably similar, as are their corresponding feedback coefficients for the money equation. Such robustness is an argument in favor of the validity of both weak exogeneity and the additional simplifications entailed by (12) relative to Table 3.

Another fruitful comparison is of the static solution (14), the dynamic steady state (15), and actual real money holdings $(m-p)$. Figure 15 plots all three, where the righthand side variables in (14) and (15) are evaluated at current values, albeit with income and inflation as annual averages in order to remove the pronounced seasonality in those variables. The static equilibrium path consistently lies above actual real money. This discrepancy reflects the uniformly positive inflation rate over the sample, which contrasts with the zero inflation rate assumed in the static solution. By comparison, real money and the dynamic steady state are quite similar: deviations between them are typically $10 \%$ and never more than $25 \%$, with deviations lasting a year or two at a time; see Figure 16. By comparison, Ericsson, Hendry, and Tran (1994) find that disequilibria in U.K. narrow money holdings over roughly the same sample are often more than $25 \%$ and sometimes even exceed $50 \%$. Such large disequilibria probably reflect the small costs of being out of equilibrium as much as the size of the shocks that created the disequilibria; cf. Hendry (1995, p. 582).

\section{Statistical Properties of the Model}

Statistically, the ECM in (12) appears reasonably well specified. The restrictions in (12) are not rejected relative to the unrestricted ECM in Table 3 (Inn), and no diagnostic test is significant. Lagrange multiplier tests for a variety of omitted variables in (12) are likewise not rejected. Specifically, $F$-statistics for testing the significance of $\left\{R D_{t-i}^{n}, i=\right.$ $0, \ldots, 4\},\left\{R S_{t-i}^{n}, i=0, \ldots, 4\right\},\left\{e_{t-i}, i=0, \ldots, 4\right\}, D S_{t}$, and $\left\{D_{89 t} \cdot Q_{t-i}, i=\right.$ $0, \ldots, 3\}$ are $F(5,56)=1.51[0.20], F(5,56)=0.24[0.94], F(5,56)=0.31$ [0.90], $F(1,60)=0.89[0.35]$, and $F(4,57)=1.52[0.21]$ respectively; and a test of their joint 


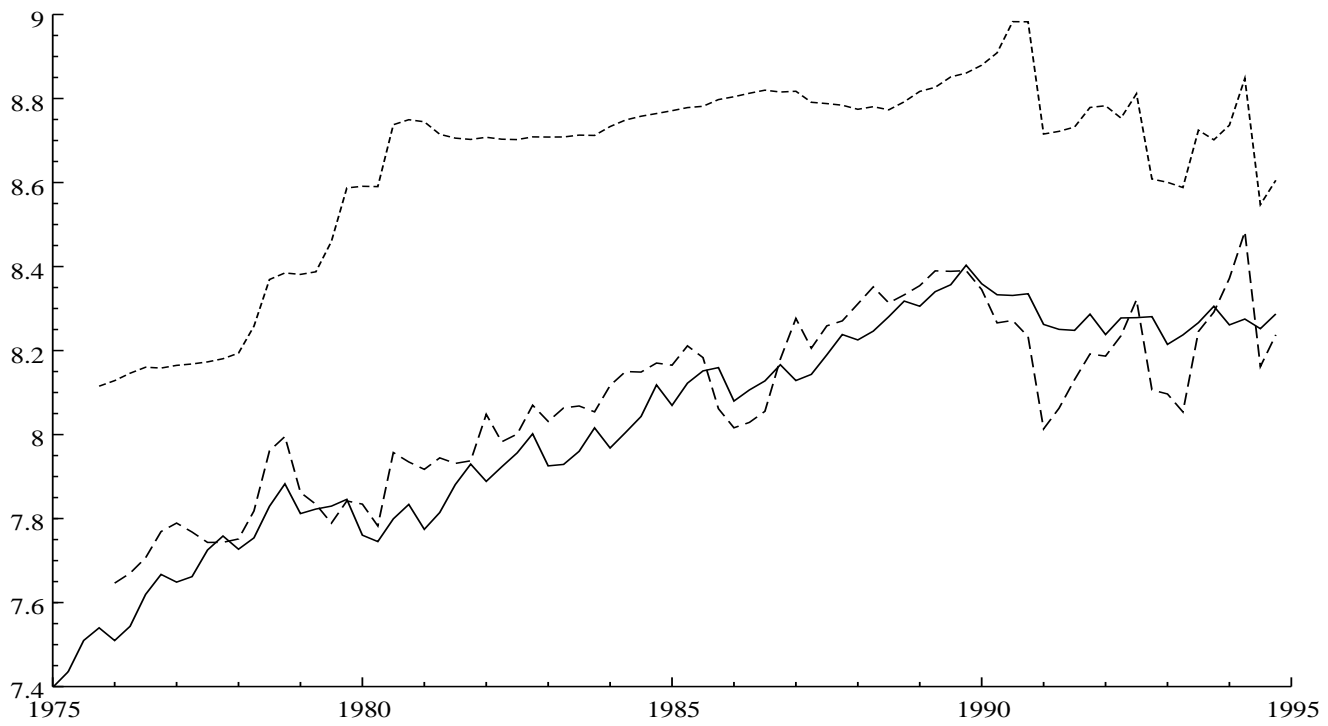

Figure 15: Actual real money $(m-p)(-)$, the static solution $(m-p)^{s}(---)$, and the dynamic solution $(m-p)^{d}(--)$.

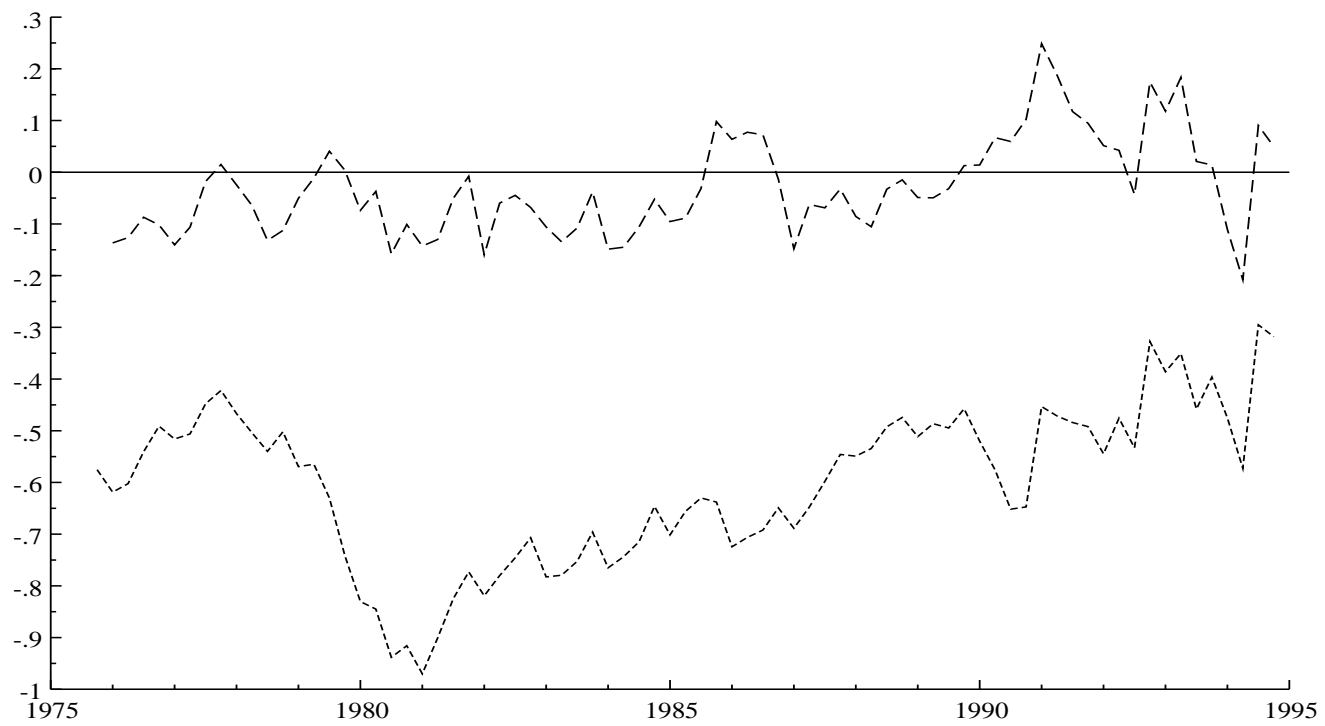

Figure 16: Deviations between money and the static solution $(m-p)-(m-p)^{s}(---)$ and between money and the dynamic solution $(m-p)-(m-p)^{d}(--)$. 
significance yields $F(20,41)=0.86$ [0.64]. The variables $R D^{n}$ and $R S^{n}$ are the interest rates on demand deposits and savings deposits, net of withholding tax.

Parameter constancy is a critical issue for money demand equations. Recursive least squares and the associated sequences of test statistics provide incisive tools for investigating constancy, with graphs efficiently summarizing the large volume of output. Figures 17-21 show the recursively estimated coefficients of variables in (12) and plusor-minus twice their recursively estimated standard errors, denoted $\hat{\beta}_{t}$ and $\hat{\beta}_{t} \pm 2 \operatorname{ese}\left(\hat{\beta}_{t}\right)$ in a frequently used notation. Coefficients vary only slightly relative to their ex ante standard errors, and both the error correction term and $R T_{t}^{n}$ are highly significant by $1985 .^{14}$

Figure 22 plots the one-step residuals and the corresponding equation standard errors, and the latter vary little numerically. Figure 23 plots the sequentially estimated one-period ahead Chow (1960) statistics, and Figure 24 plots the "break-point" Chow (1960) statistics for the sequence $\{1981(2)-1993(4), 1981(3)-1993(4), 1981(4)-1993(4), \ldots, 1993(3)-$ 1993(4), 1993(4)\}. While two of the fifty-five one-period ahead Chow statistics (i.e., about $4 \%$ ) are statistically significant, none of the break-point Chow statistics are significant at even their one-off 5\% levels. That is, no split of the sample would obtain a rejection. Figures 25 and 26 respectively plot the actual and fitted values for $\Delta m_{t}$ and the corresponding residuals, showing how well (12) explains the data.

The empirical stability of (12) suggests that the process determining broad money demand in Greece has remained largely unchanged during the 1980s and 1990s, even while inflation and interest rates have varied and financial liberalization has occurred. In particular, the explanation for the recent stagnation of real money demand lies in what has happened to actual income, inflation, and interest rates. Holdings of broad money balances appear to be endogenously determined by the private sector, while the government controls and/or regulates interest rates and the financial market's structure. With the money stock being endogenous, it cannot be controlled by the government, although the government can target it through its policies for interest rates and financial structure inter alia. See Hendry and Mizon (1995) for further discussion.

\section{Caveats and Implications}

Several remarks on the interpretation of the above results may be helpful. Issues include weak exogeneity, the Lucas critique, inversion of the estimated money demand equation, and encompassing of other empirical models.

\footnotetext{
${ }^{14}$ In estimating (12) recursively, the coefficients on $\Delta S T_{t}, \Delta_{2} S T_{t-2}, S_{t}$, and $D E_{t}$ are taken as given at their full-sample estimates. This modification is helpful because these variables become nonzero only well after the initial subsample used for recursive estimation. Treating their coefficients as known may bias the Chow statistic towards rejection because extra degrees of freedom are assumed in calculating that statistic. However, that bias did not matter in practice.
} 

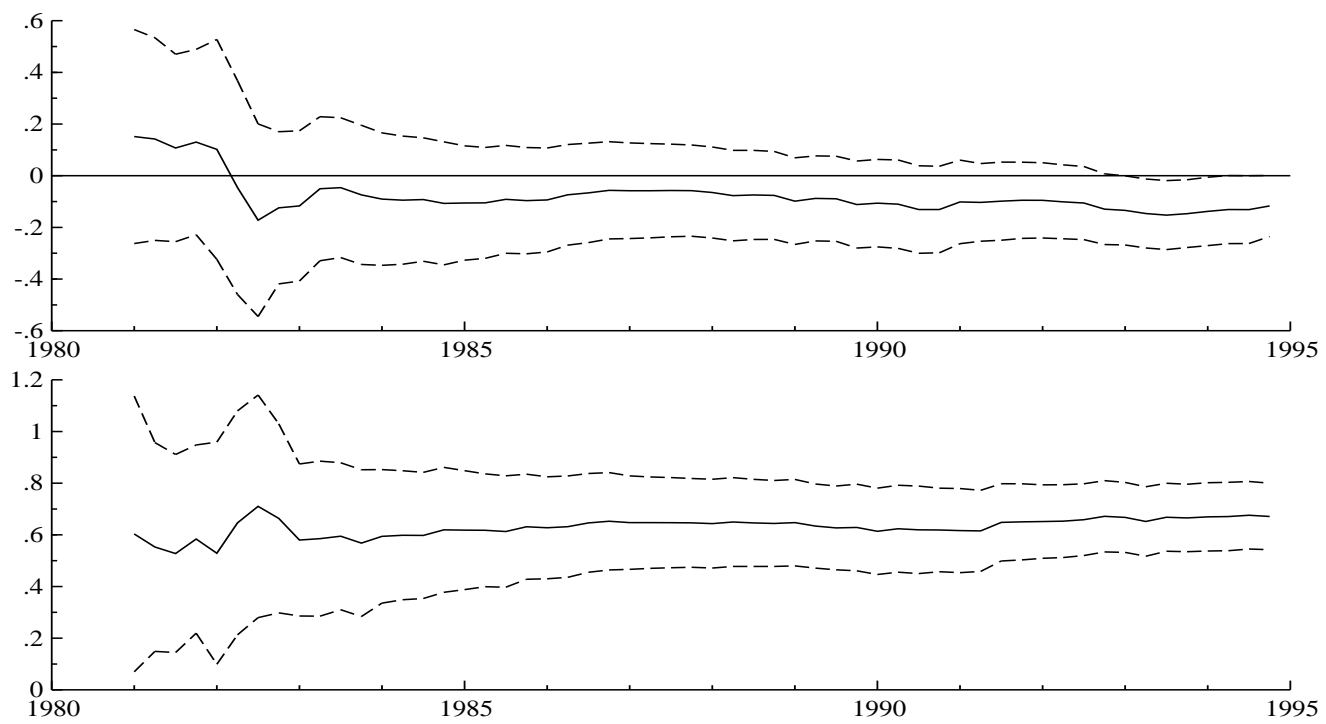

Figure 17: Equation (12): recursive estimates (-) of the coefficients of $\Delta m_{t-1}$ and $\Delta m_{t-2}$ with \pm 2 estimated standard errors (- $)$.

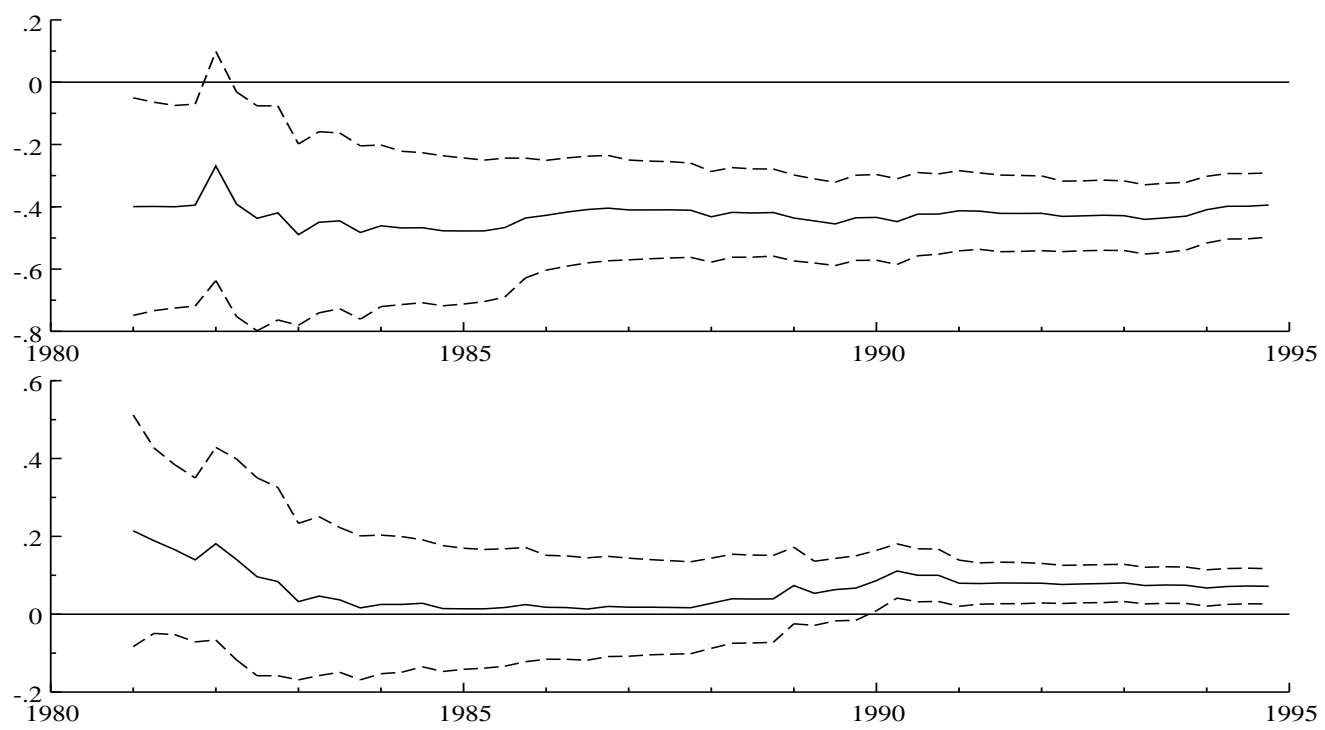

Figure 18: Equation (12): recursive estimates (-) of the coefficients of $\Delta_{2} p_{t}$ and $\Delta y_{t}$ with \pm 2 estimated standard errors (- $)$. 


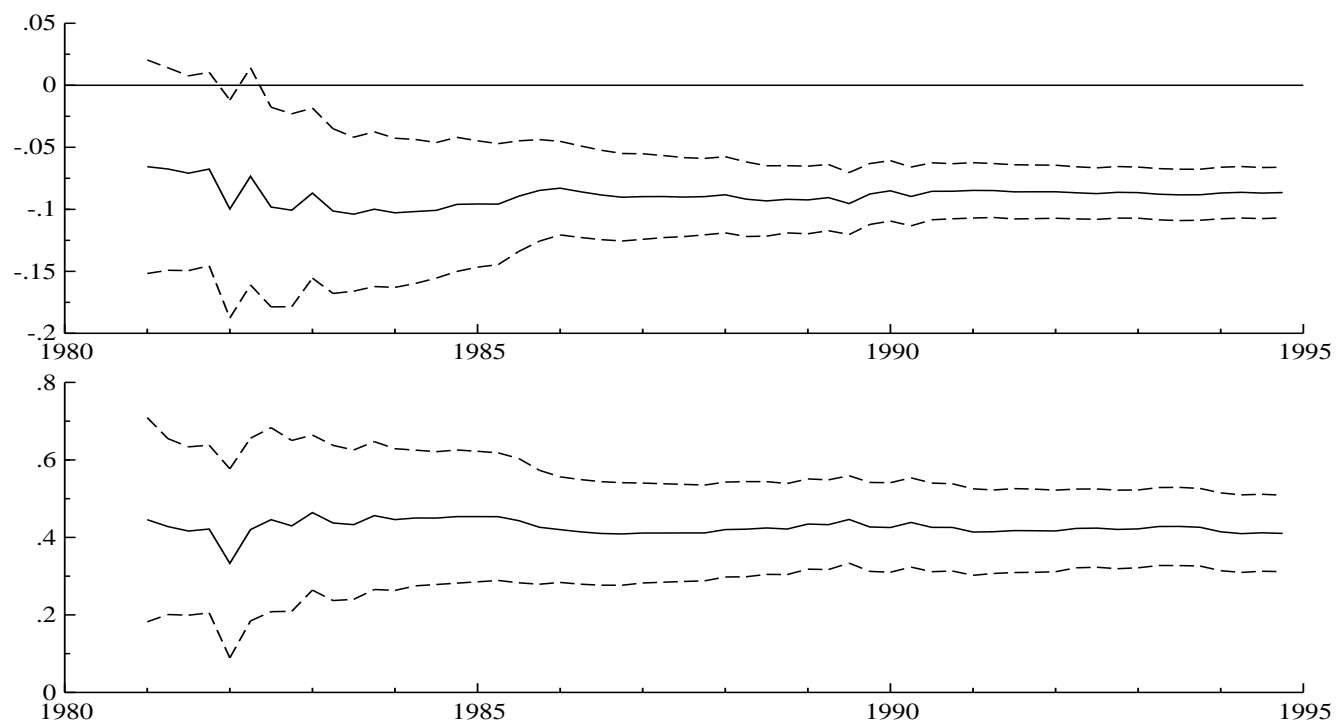

Figure 19: Equation (12): recursive estimates (-) of the coefficients of $(m-p-y)_{t-1}$ and $R T_{t}^{n}$ with \pm 2 estimated standard errors $(--)$.

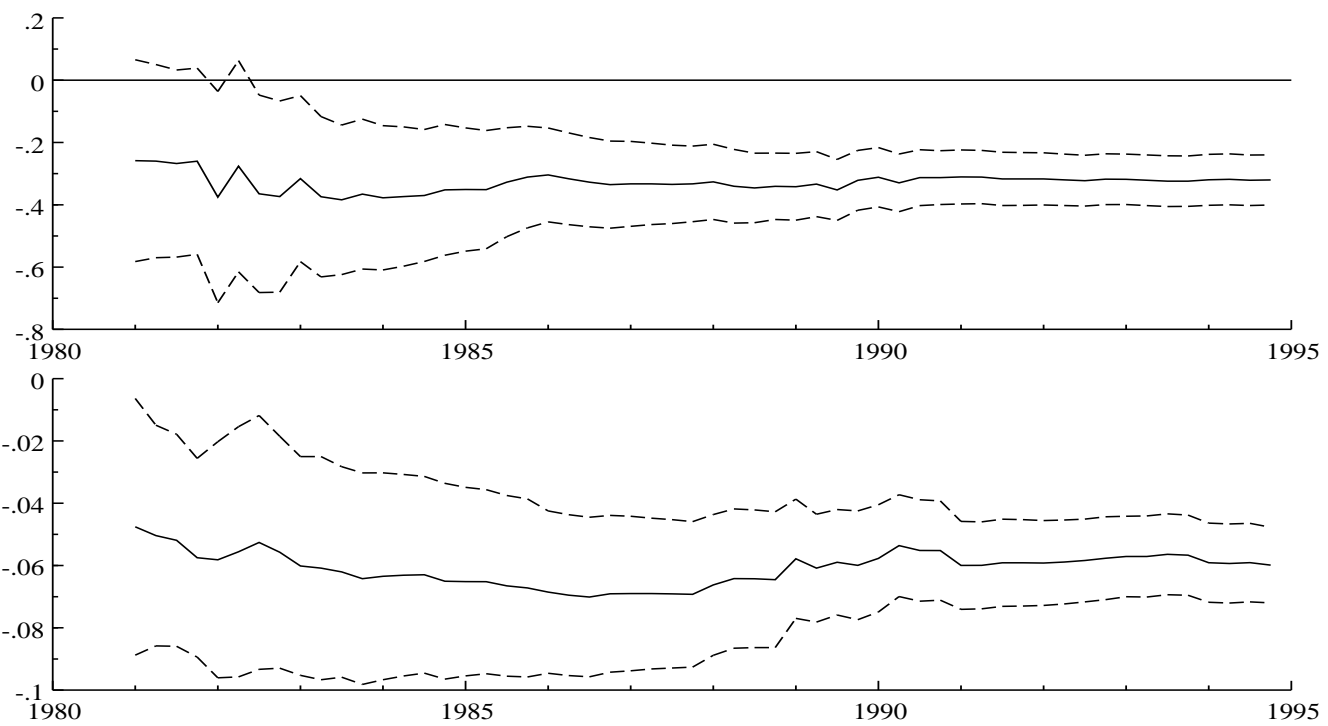

Figure 20: Equation (12): recursive estimates (-) of the coefficients of the constant and $Q_{t-1}$ with \pm 2 estimated standard errors $(--)$. 

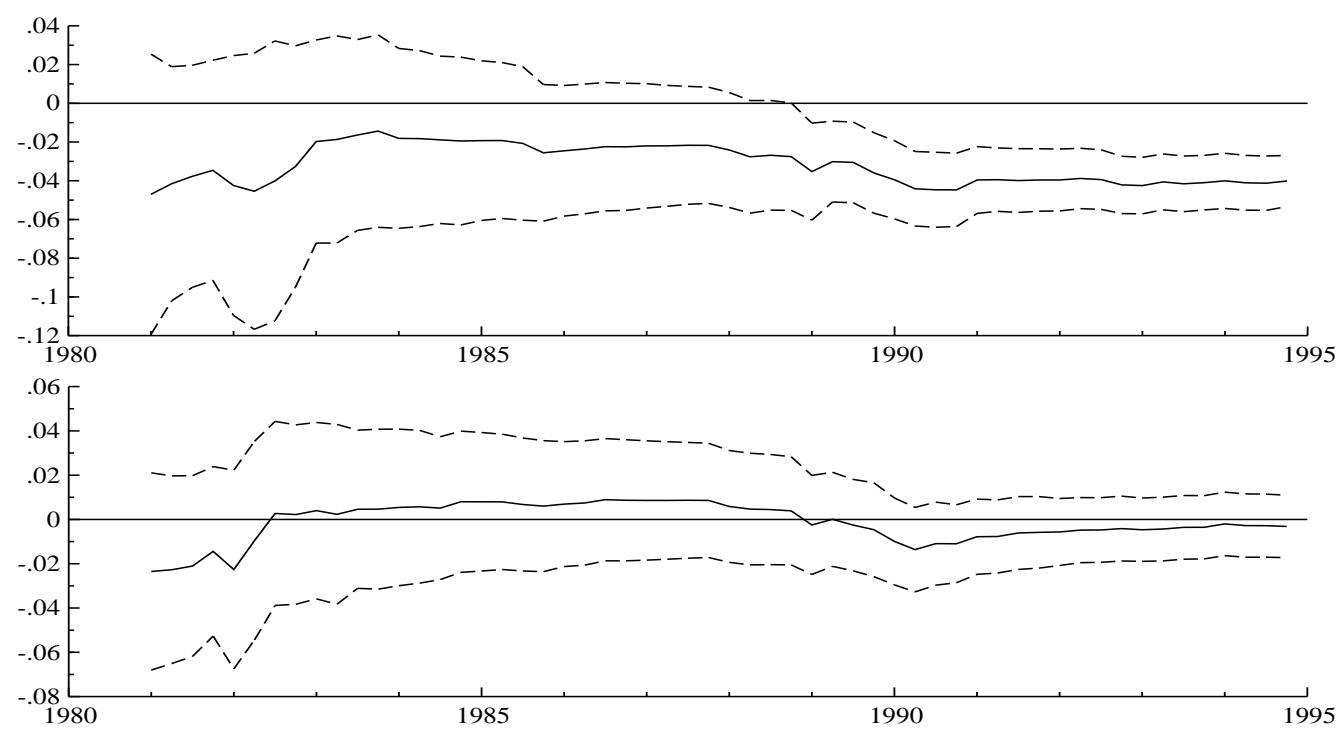

Figure 21: Equation (12): recursive estimates (-) of the coefficients of $Q_{t-2}$ and $Q_{t-3}$ with \pm 2 estimated standard errors (- $)$.

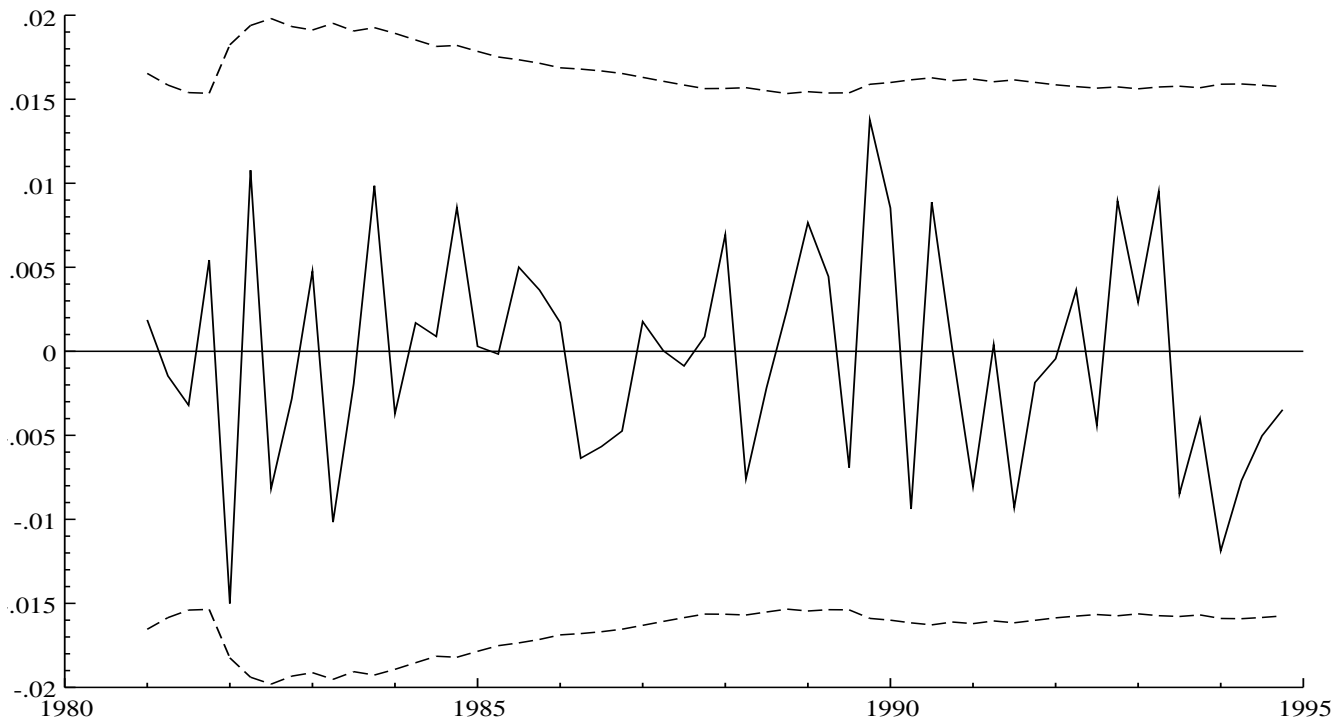

Figure 22: One-step residuals (-) from equation (12), with $0 \pm 2 \hat{\sigma}_{t}(--)$. 


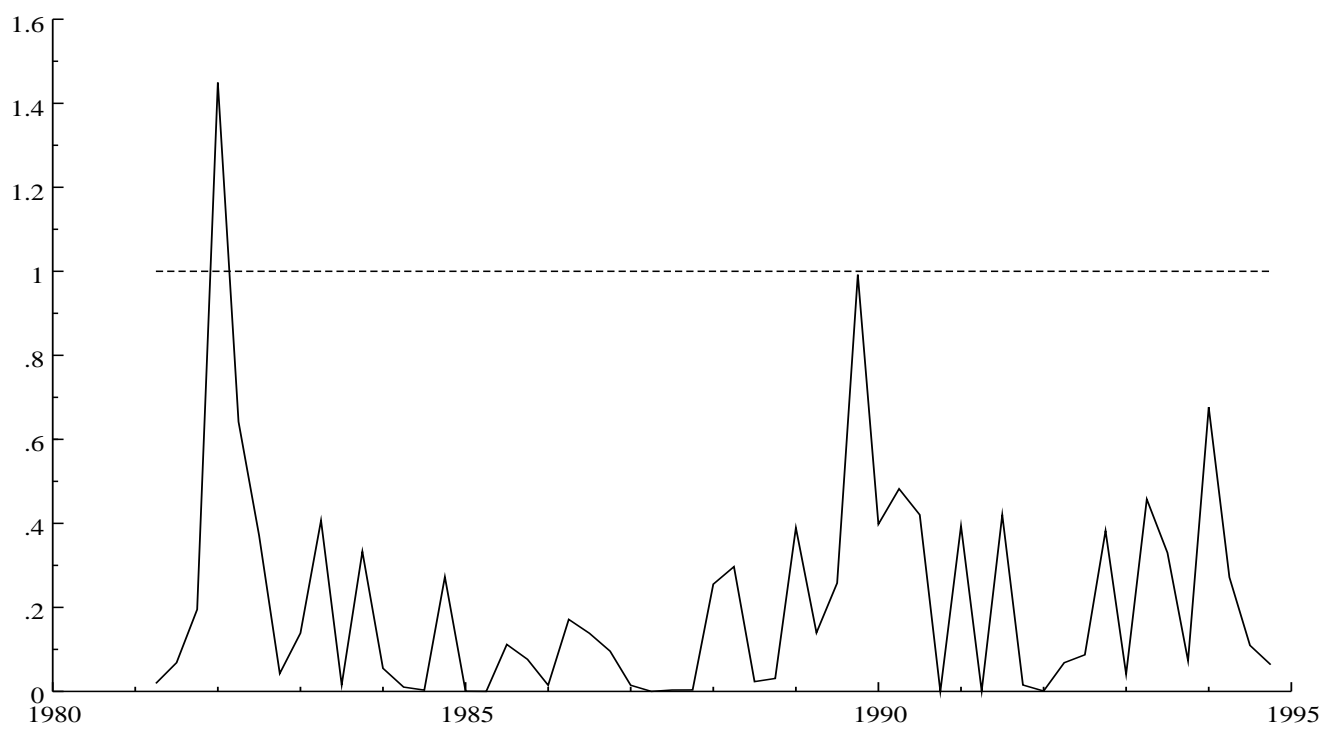

Figure 23: One-step Chow statistics (-) for equation (12), normalized by their one-off $5 \%$ critical values (- - ).

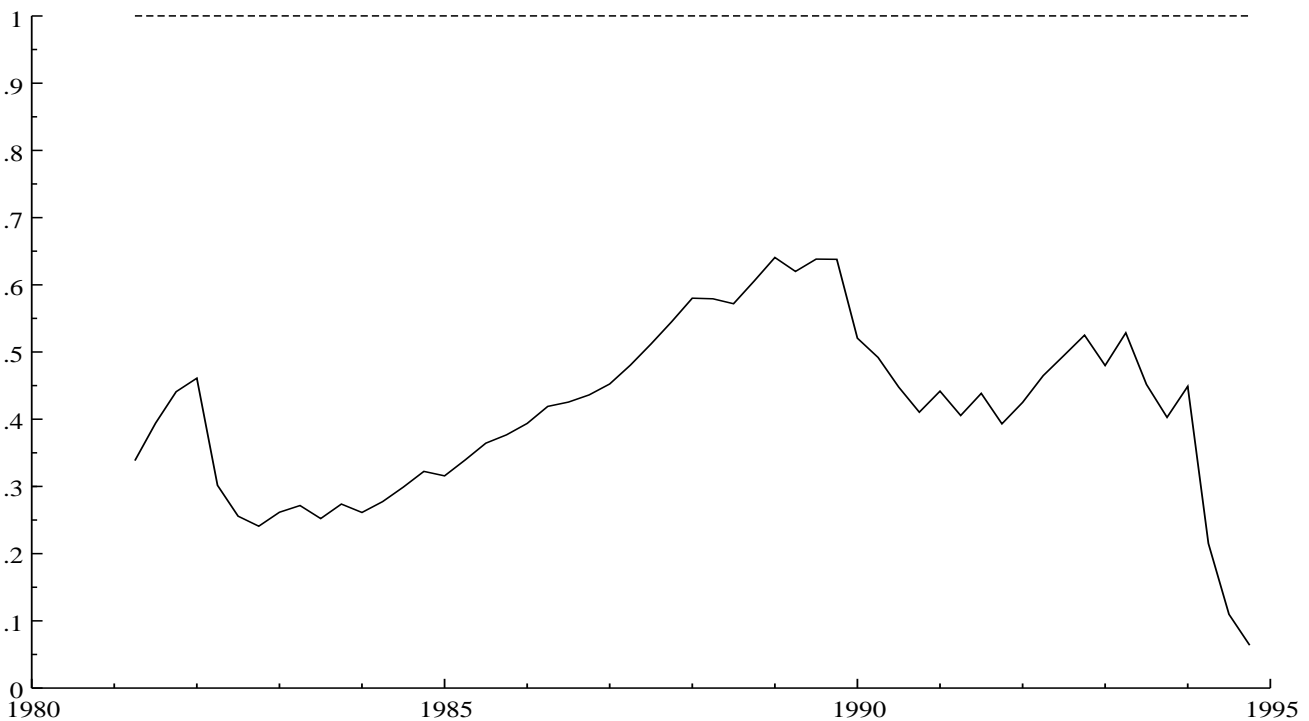

Figure 24: Break-point Chow statistics (-) for equation (12), normalized by their one-off $5 \%$ critical values (- - ). 


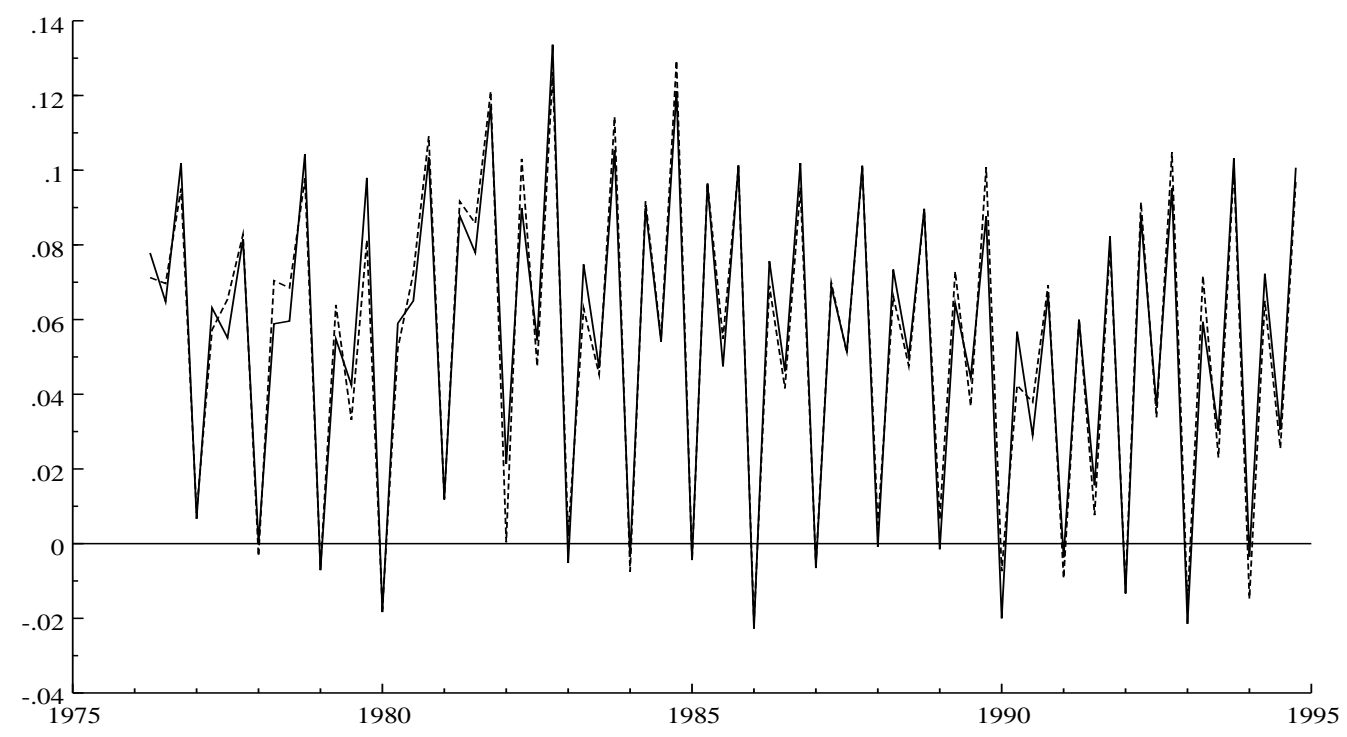

Figure 25: Actual (-) and fitted (- - ) values for $\Delta m_{t}$ from equation (12).

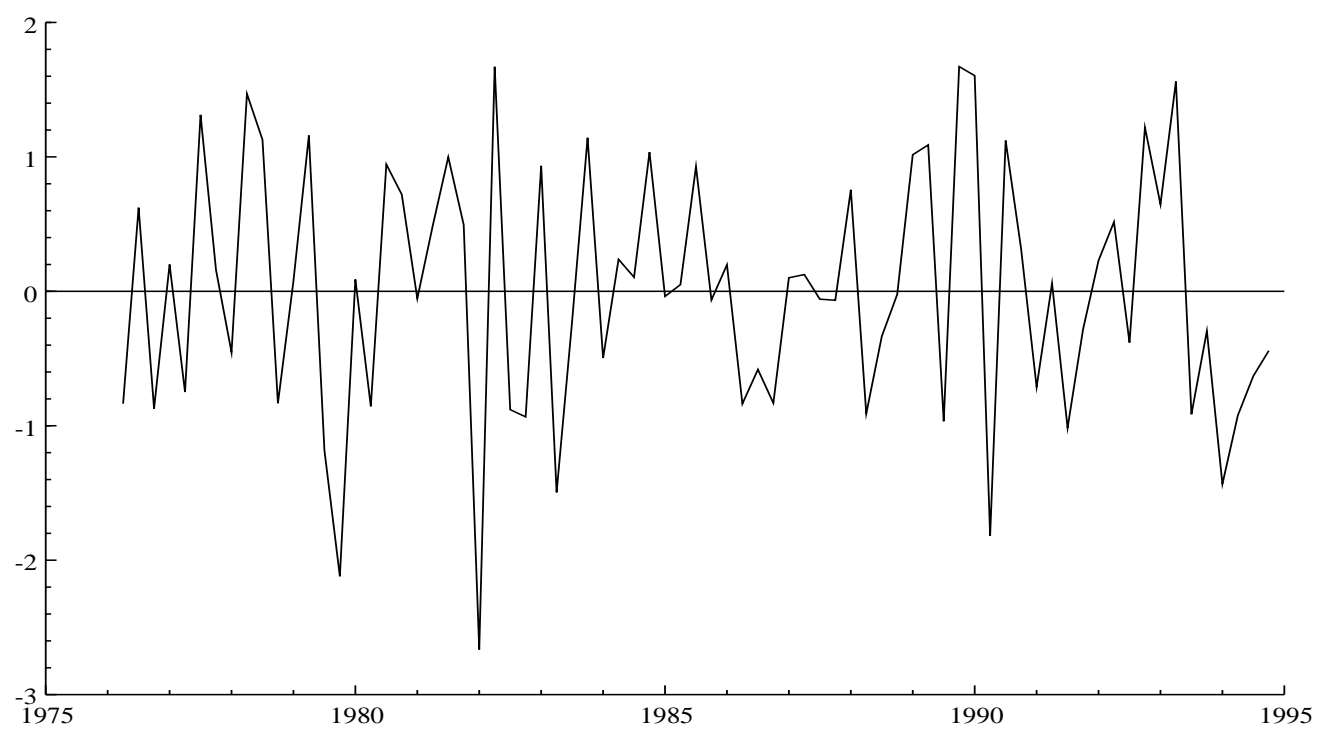

Figure 26: Scaled residuals from equation (12). 
Section III established the weak exogeneity of output, inflation, and interest rates for the long-run parameters of the money demand relation. However, ex ante forecasting and counterfactual simulations for policy analysis are subject to several important caveats. First, ex ante forecasting requires specifying the paths for the "right-hand side" variables - output, inflation, and interest rates. Further, if multi-step ahead forecasts of money demand are constructed conditional on those future paths of the right-hand side variables, Granger noncausality from $m$ to $p, y, R T^{n}, S T$, and $S R$ is assumed, either implicitly or explicitly. While weak exogeneity precludes explicit feedback in levels via the error correction term, it does not exclude feedback through lagged growth rates. Empirically, one would want to establish Granger noncausality before conducting conditional forecasting, or to develop models of $p, y, R T^{n}, S T$, and $S R$ to permit jointly forecasting all variables involved. On the latter approach, see Hendry and Mizon (1993) and Hendry and Doornik (1994) for U.K. money demand and Juselius (1993) for Danish money demand.

Counterfactual (policy) experiments require showing that the Lucas critique does not hold for the relevant class of interventions. That is, the money demand function should remain empirically constant, even when the marginal processes generating the other variables change. Formal tests for refuting the Lucas critique empirically appear in Hendry (1988) and Engle and Hendry (1993), and they would be of interest to conduct for (12). The empirical constancy of (12) in the presence of financial deregulation is partial evidence against the Lucas critique applying here.

"Inversion" of money demand equations is a frequently occurring but empirically questionable practice. Estimated money demand functions are inverted to obtain the price level as a function of money (common among macro-economists) or to obtain the interest rate as a function of money (common among macro-modelers). However, inversion of a conditional money demand model such as (12) in general obtains coefficients that are not functions of the inverse coefficients of the money demand model alone. That is, inversion of a stochastic conditional model is not a simple renormalization of coefficients. Statistically, inversion implies a refactorization of the joint distribution of the variables as the product of the conditional distribution of inflation given the other variables and the "marginal" distribution of the other variables. Switching the roles of $\Delta m_{t}$ and $\Delta p_{t}$ in (12) and re-estimating as a conditional inflation equation obtains the following:

$$
\begin{aligned}
& \Delta p_{t}=\underset{(0.139)}{0.061} \Delta p_{t-1}-\underset{(0.133)}{0.558} \Delta m_{t}-\underset{(0.088)}{0.041} \Delta m_{t-1}+\underset{(0.126)}{0.381 \Delta m_{t-2}} \\
& \underset{(0.034)}{0.041} \Delta y_{t}-\underset{(0.191)}{0.078} \Delta S T_{t}+\underset{(0.146)}{0.445 \Delta \Delta_{2} S T_{t-2}}-\underset{(0.008)}{0.015 D E_{t}} \\
& -0.057(m-p-y)_{t-1}+0.317 R T_{t}^{n}-0.595 S_{t} \\
& (0.017) \quad(0.080) \quad(0.179) \\
& -0.205-0.070 Q_{t-1}-0.019 Q_{t-2}-0.031 Q_{t-3} \\
& \begin{array}{lll}
(0.065) \quad(0.013) & (0.010) & (0.010)
\end{array}
\end{aligned}
$$




$$
\begin{aligned}
& T=75[1976(2)-1994(4)] \quad R^{2}=0.836 \quad \hat{\sigma}=0.963 \% \quad d w=2.18 \\
& A R: F(5,55)=0.99 \quad A R C H: F(4,52)=0.37 \\
& \text { Normality }: \chi^{2}(2)=6.63^{*} \quad R E S E T: F(1,59)=1.14 \\
& \text { Hetero }: F(24,35)=0.69 .
\end{aligned}
$$

The fit of (16) is not much better than that of the marginal equation for inflation in the vector autoregression $(\hat{\sigma}=1.07 \%)$, and several coefficients in (16) do not make economic sense. In particular, both the contemporaneous change in broad money and the error correction term have negative coefficients, implying that increases in money and in "excess" holdings of money dampen inflation. Further, the money demand equation (12) is empirically constant, but its inversion (16) need not be so.

In principle, statistical comparison of models (encompassing) can help identify weaknesses of the models being tested, and so indicate directions for their improvement. However, two practical difficulties prohibit calculating encompassing tests against other researchers' models: no other empirical models currently exist that use the new measure of M3, and encompassing statistics for comparing models of different aggregates have not yet been developed.

Models do exist for other measures of money. For the old measure of M3, Prodromidis (1984) estimates static and partial adjustment models over 1966-1977, a sample that is nearly non-overlapping with ours. Based on an EconLit bibliographic search, Prodromidis (1984) appears to be the only published empirical analysis of Greek M3 demand. By contrast, many models of M1 have been published, with (e.g.) Psaradakis (1993) following a similar methodology to the one adopted above.

While currently no alternate models exist to encompass, some directions for improving (12) are clear. In particular, for the returns on new assets and Treasury bills, their more gradual introduction in the model may better capture individuals' actual responses. Learning-adjusted interest rates are one simple, intuitive formulation; see Hendry and Ericsson (1991b) and Baba, Hendry, and Starr (1992).

\section{Concluding Remarks}

The estimated conditional model of money demand in Greece is remarkably stable and otherwise well-specified over the period 1976-1994. The model's empirical constancy holds in the face of large fluctuations in the inflation rate and a progressive - albeit slow - liberalization of the financial system. Even so, the fundamental changes currently underway in the Greek financial system could alter the structure of the money demand function and, as a consequence, further complicate the conduct of monetary policy. With restrictions on external capital flows removed and financial deregulation in Greece ongoing, higher returns on assets inside M3 may increase the demand for money, while greater availability of alternative assets (both domestic and foreign) may lower demand. For our 
sample, the exchange rate did not significantly affect money demand once inflation was included. With greater capital mobility, however, returns on foreign assets (and hence foreign interest rates and the exchange rate) are likely to influence money demand, as did the increased availability of Treasury bills in the early 1990s. For money demand in the United States and the United Kingdom, Baba, Hendry, and Starr (1992) and Hendry and Ericsson (1991b) show how the empirical adjustments to one financial innovation may guide the specification of effects from future innovations. For Greece, the presence of the spreads in the estimated ECM suggests the potential empirical role of new alternative assets in the demand for broad money. 


\section{Appendix I: Data Definitions}

This appendix describes the data in greater detail. It lists the definitions used and gives their units and sources. All data are quarterly and seasonally unadjusted, and the sample period is from the first quarter of 1975 through the fourth quarter of 1994. The data were kindly provided to us by the Bank of Greece. To the extent possible, publicly available sources are given for the series.

\section{Monetary Aggregates and Their Components}

Definition. The components of the broad money aggregate M3 $(M)$ are currency in circulation $(C C)$, demand (or sight) deposits $(D D)$, savings deposits $(S D)$, time deposits $(T D)$, bank bonds $(B B)$, and repurchase agreements (repos) $(R E P)$. Demand deposits, savings deposits, and time deposits are those held by individuals and private enterprises. Narrow money (M1) is currency in circulation plus demand deposits. In our sample, bank bonds were introduced in 1975(4), and repos in 1990(4).

Units. Billion $\left(10^{9}\right)$ Drachmas. All figures are end-of-period balances.

Source. Monthly Statistical Bulletin, the Bank of Greece (Table 1 for $C C$ and $D D$, Table 12 for $S D$ and TD); and Economic Bulletin, the Bank of Greece (Table III.1 for $B B$ and $R E P$ ).

Treasury Bills

Definition. The stock of Treasury bills and one-year government bonds held by the private sector $(T B)$.

Units. Billion $\left(10^{9}\right)$ Drachmas, end-of-period balances.

Source. Economic Bulletin, the Bank of Greece (Table III.1).

\section{$\underline{\text { Interest Rates }}$}

Definition. Interest rates on demand deposits $(R D)$, savings deposits with commercial banks $(R S)$, time deposits at 12-month maturity for individuals and private enterprises $(R T)$, repurchase agreements $(R R)$, and Treasury bills of 12-month maturity $(R B)$. Each rate is a weighted average of the various interest rates paid on the given financial instrument.

Units. Annual rate expressed as a fraction, calculated as the arithmetic average of monthly (average) rates.

Source. Bank of Greece ( $R D$ and RR); Monthly Statistical Bulletin, the Bank of Greece (Table 17 for $R S$ and $R T$ ); and Economic Bulletin, the Bank of Greece (Table III.4 for $R B)$. 


\section{Net Interest Rates}

Definition. Interest rates, net of withholding tax, on demand deposits $\left(R D^{n}\right)$, savings deposits $\left(R S^{n}\right)$, time deposits $\left(R T^{n}\right)$, and repurchase agreements $\left(R R^{n}\right)$. The net interest rate is calculated as the gross interest rate times $(1-\tau)$, where $\tau$ is the withholding tax rate on interest payments. The government imposed a 10 percent withholding tax on bank deposits in 1991(1). That tax was raised to 12 percent in 1992(3) and to 15 percent in 1992(4). In 1994(2), the government also imposed a withholding tax of 15 percent on repurchase agreements.

Units. Annual rate expressed as a fraction.

Source. Bank of Greece $(\tau)$.

\section{Consumer Price Index}

Definition. The general consumer price index $(P)$.

Units. $1988=100$. The series was calculated as the arithmetic average of monthly values. To match the quarterly GDP figures, which have 1970 as their base year, the CPI series was then converted to base year $1970=100$ by dividing by $6.333 / 100$.

Source. Monthly Statistical Bulletin, National Statistical Service of Greece (Table 75).

\section{$\underline{\text { Real Output }}$}

Definition. Real gross domestic product (GDP) at factor cost $(Y)$. This is the only real output variable for which a quarterly series was available. Until 1987, the series coincides with that reported by the National Statistical Service in its Monthly Statistical Bulletin. From 1987 onwards, the series consists of figures adjusted by the Bank of Greece to be consistent with the revised annual GDP figures for the new national accounts. The National Statistical Service's Monthly Statistical Bulletin reports real GDP through 1991(1), but based on the old national accounts. This latter series is denoted $Y^{o l d}$.

Units. Million Drachmas in 1970 prices.

Source. Monthly Statistical Bulletin, National Statistical Service of Greece (Table 97 for $Y$ and $Y^{\text {old }}$ ); and the Bank of Greece (for $Y$ from 1987 onwards).

\section{The Nominal Effective Exchange Rate}

Definition. Trade-weighted nominal effective exchange rate index $(E)$. The index includes the currencies of fifteen "competitor countries," and the weights are based on non-oil trade flows during 1981-1984.

Units. $1986=100$.

Source. Economic Bulletin, the Bank of Greece (Table II.2). 
Dummy Variables

Definition. The dummy variables $D E, D S$, and $D_{89}$ equal unity for the periods 1982(4)1983(1), 1994(3)-1994(4), and 1989(1)-1994(4) respectively, and are zero otherwise.

\section{Appendix II: Design of the Empirical ECM}

This appendix discusses the steps taken to obtain the ECM in (12). The simplification to (12) has numerous motivations. Because of its parsimony and more orthogonal regressors, (12) is more easily interpreted than the unrestricted ADL or the vector autoregression. Also, the coefficients in (12) are more precisely estimated than those in the ADL and the vector autoregression, providing tighter inferences generally and higher potential power for tests of mis-specification.

The initial six-variable, fourth-order vector autoregression for the system cointegration analysis was not simplified, either in terms of variables or in terms of lag length. All six variables appear to matter in the long run (Table 2 above). The Schwarz criterion does fall monotonically in the sequential reduction from a fourth-order to a first-order vector autoregression. However, many sets of variables at a given lag length are statistically significant, so the lag length for the vector autoregression is kept at four.

Instead, simplification begins with weak exogeneity and then progresses through lag reduction and variable transformation. Having tested for and found weak exogeneity for real GDP, inflation, and the interest rates (Table 2), a fourth-order autoregressive distributed lag for money is simplified to the ECM in (12). Table 3 above lists the estimates of the coefficients for the fourth-order ADL, where the ADL has been transformed into an unrestricted ECM representation. The following variables do not appear either numerically or statistically significant in that representation.

(i) The lags $p_{t-1}$ and $y_{t-1}$ and the spread $S R_{t}$ (all being long-run variables);

(ii) All current and lagged values of $\Delta R T^{n}$ and $\Delta S R$; and

(iii) The lags $\Delta m_{t-3}, \Delta y_{t-1}, \Delta y_{t-2}$, and $\Delta y_{t-3}$.

Three additional sets of reductions are considered:

(iv) The coefficients on $\Delta p_{t}$ and $\Delta p_{t-1}$ are equal and those on the remaining lags of $\Delta p_{t}$ are zero, in which case inflation enters as the single variable $\Delta_{2} p_{t}$;

(v) The coefficients on $\Delta S T_{t-2}$ and $\Delta S T_{t-3}$ are equal and the one on $\Delta S T_{t-1}$ is zero, in which case this spread enters as $\Delta S T_{t}$ and $\Delta_{2} S T_{t-2}$; and

(vi) The dummies $D_{89 t} \cdot Q_{t-i}(i=0,1,2,3)$ and $D S_{t}$ have coefficients of zero.

Treated sequentially, these six restrictions obtain the following seven models. 
Model 1: The unrestricted ECM in Table 3.

Model 2: Model 1, imposing long-run price and income homogeneity and long-run spread equality.

Model 3: Model 2, excluding $\left\{\Delta R T_{t-i}^{n}, \Delta S R_{t-i} ; i=0,1,2,3\right\}$.

Model 4: Model 3, excluding the lags $\Delta m_{t-3}, \Delta y_{t-1}, \Delta y_{t-2}$, and $\Delta y_{t-3}$.

Model 5: Model 4, excluding $\Delta p_{t-1}, \Delta p_{t-2}$, and $\Delta p_{t-3}$, once $\Delta p_{t}$ and $\Delta p_{t-1}$ have been transformed to $\Delta_{2} p_{t}$ and $\Delta p_{t-1}$.

Model 6: Model 5, excluding $\Delta S T_{t-1}$ and $\Delta S T_{t-3}$, once $\Delta S T_{t-2}$ and $\Delta S T_{t-3}$ have been transformed to $\Delta_{2} S T_{t-2}$ and $\Delta S T_{t-3}$.

Model 7: Model 6, excluding $D_{89 t} \cdot Q_{t-i}(i=0,1,2,3)$ and $D S_{t}$.

So, for example, Model 2 is Model 1 plus reduction (i); Model 3 is Model 1 plus reductions (i)-(ii); and Model 3 is also Model 2 plus reduction (ii). Table 3 and equation (12) list the estimates for Models 1 and 7 and show how little the estimates change from imposing the six reductions.

To facilitate formally assessing whether or not the sequence of reductions (i)-(vi) is valid, and if not, where not, statistics associated with the implied reductions are calculated for all model pairs, and not only for adjacent models. Table II.1 reports this information, including the estimated equation standard error $\hat{\sigma}$ and the Schwarz criterion for each model, the $F$ statistics for all model pairs, and the associated tail probability values. The equation standard error is relatively constant across the entire simplification path, and the Schwarz criterion declines steadily throughout. Only one reduction (of excluding current and lagged values of $\Delta R T^{n}$ and $\Delta S R$ ) is statistically significant at the 5\% level; and it is only barely so, and only when considered by itself and not in conjunction with additional reductions. Other orderings of (i)-(vi) generate somewhat different statistics, but those resulting statistics are unlikely to be highly statistically significant because the reduction of (i)-(vi) as a whole appears valid, with $F(25,36)=1.23$ and a $p$-value of 0.28 . 
Table II.1.

$F$ and Related Statistics for the Sequential Reduction

from the Fourth-order ADL Model in Table 3 to the final ECM (12)

\begin{tabular}{|c|c|c|c|c|c|c|c|c|c|}
\hline \multicolumn{4}{|c|}{ Null Hypothesis } & \multicolumn{6}{|c|}{ Maintained Hypothesis (Model Number) } \\
\hline Model & $k$ & $\hat{\sigma}$ & $S C$ & 1 & 2 & 3 & 4 & 5 & 6 \\
\hline 1 & 39 & $0.778 \%$ & -8.20 & $\begin{array}{l}- \\
-\end{array}$ & & & & & \\
\hline$\downarrow$ (i) & & & & - & & & & & \\
\hline 2 & 36 & $0.750 \%$ & -8.37 & $\begin{array}{c}0.09 \\
{[0.96]}\end{array}$ & & & & & \\
\hline$\downarrow$ (ii) & & & & $(3,36)$ & & & & & \\
\hline $\begin{array}{l}3 \\
\downarrow \quad \text { (iii) }\end{array}$ & 28 & $0.825 \%$ & -8.45 & $\begin{array}{c}1.53 \\
{[0.16]} \\
(11,36)\end{array}$ & $\begin{array}{c}2.23 \\
{[0.05]} \\
(8,39)\end{array}$ & & & & \\
\hline $\begin{array}{l}4 \\
\downarrow \text { (iv) }\end{array}$ & 24 & $0.833 \%$ & -8.58 & $\begin{array}{c}1.50 \\
{[0.16]} \\
(15,36)\end{array}$ & $\begin{array}{c}2.00 \\
{[0.05]} \\
(12,39)\end{array}$ & $\begin{array}{c}1.27 \\
{[0.30]} \\
(4,47)\end{array}$ & & & \\
\hline $\begin{array}{l}5 \\
\downarrow \quad(\mathrm{v})\end{array}$ & 21 & $0.817 \%$ & -8.74 & $\begin{array}{c}1.31 \\
{[0.24]} \\
(18,36)\end{array}$ & $\begin{array}{c}1.67 \\
{[0.10]} \\
(15,39)\end{array}$ & $\begin{array}{c}0.85 \\
{[0.55]} \\
(7,47)\end{array}$ & $\begin{array}{c}0.29 \\
{[0.83]} \\
(3,51)\end{array}$ & & \\
\hline $\begin{array}{l}6 \\
\downarrow \quad(\mathrm{vi})\end{array}$ & 19 & $0.805 \%$ & -8.84 & $\begin{array}{c}1.20 \\
{[0.31]} \\
(20,36)\end{array}$ & $\begin{array}{c}1.50 \\
{[0.15]} \\
(17,39)\end{array}$ & $\begin{array}{c}0.71 \\
{[0.70]} \\
(9,47)\end{array}$ & $\begin{array}{c}0.25 \\
{[0.94]} \\
(5,51)\end{array}$ & $\begin{array}{c}0.21 \\
{[0.81]} \\
(2,54)\end{array}$ & \\
\hline 7 & 14 & $0.813 \%$ & -9.03 & $\begin{array}{c}1.23 \\
{[0.28]} \\
(25,36)\end{array}$ & $\begin{array}{c}1.48 \\
{[0.14]} \\
(22,39)\end{array}$ & $\begin{array}{c}0.88 \\
{[0.59]} \\
(14,47)\end{array}$ & $\begin{array}{c}0.70 \\
{[0.72]} \\
(10,51)\end{array}$ & $\begin{array}{c}0.92 \\
{[0.50]} \\
(7,54)\end{array}$ & $\begin{array}{c}1.24 \\
{[0.30]} \\
(5,56)\end{array}$ \\
\hline
\end{tabular}

Notes

1. The first four columns report the model number (with reduction number), and for that model: the number of unrestricted parameters $k$, the estimated equation standard error $\hat{\sigma}$, and the Schwarz criterion $S C$. The text of Appendix II defines the models and reductions.

2. The three entries within a given block of numbers in the last six columns are: the $F$ statistic for testing the null hypothesis (indicated by the model number to the left of the entry) against the maintained hypothesis (indicated by the model number above the entry), the tail probability associated with that value of the $F$ statistic (in square brackets), and the degrees of freedom for the $F$ statistic (in parentheses). 


\section{References}

Akerlof, G. A. (1979) "Irving Fisher on His Head: The Consequences of Constant Threshold-target Monitoring of Money Holdings," Quarterly Journal of Economics, 93, 2, 169-187.

Akerlof, G. A., and R. D. Milbourne (1980) "Irving Fisher on His Head II: The Consequences of the Timing of Payments for the Demand for Money," Quarterly Journal of Economics, 95, 1, 145-157.

Alogoskoufis, G. (1995) "The Two Faces of Janus: Institutions, Policy Regimes and Macroeconomic Performance in Greece," Economic Policy, 20, 147-192 (with discussion).

Baba, Y., D. F. Hendry, and R. M. Starr (1992) "The Demand for M1 in the U.S.A., 1960-1988," Review of Economic Studies, 59, 1, 25-61.

Banerjee, A., J. J. Dolado, J. W. Galbraith, and D. F. Hendry (1993) Co-integration, Error Correction, and the Econometric Analysis of Non-stationary Data, Oxford, Oxford University Press.

Banerjee, A., J. J. Dolado, D. F. Hendry, and G. W. Smith (1986) "Exploring Equilibrium Relationships in Econometrics through Static Models: Some Monte Carlo Evidence," Oxford Bulletin of Economics and Statistics, 48, 3, 253-277.

Baumol, W. J. (1952) “The Transactions Demand for Cash: An Inventory Theoretic Approach," Quarterly Journal of Economics, 66, 4, 545-556.

Boughton, J. M. (1991) "Money Demand in Five Major Industrialized Countries: Estimating and Interpreting Error Correction Models," Chapter 4 in M. P. Taylor (ed.) Money and Financial Markets, Oxford, Basil Blackwell, 109-129.

Boughton, J. M. (1993) "The Demand for M1 in the United States: A Comment on Baba, Hendry, and Starr," Economic Journal, 103, 420, 1154-1157.

Box, G. E. P., and D. A. Pierce (1970) "Distribution of Residual Autocorrelations in Autoregressive-integrated Moving Average Time Series Models," Journal of the American Statistical Association, 65, 332, 1509-1526.

de Brouwer, G., and N. R. Ericsson (1995) "Modelling Inflation in Australia," International Finance Discussion Paper No. 530, Board of Governors of the Federal Reserve System, Washington, D.C., November.

Chow, G. C. (1960) "Tests of Equality between Sets of Coefficients in Two Linear Regressions," Econometrica, 28, 3, 591-605.

Dickey, D. A., and W. A. Fuller (1981) "Likelihood Ratio Statistics for Autoregressive Time Series with a Unit Root," Econometrica, 49, 4, 1057-1072.

Doornik, J. A., and H. Hansen (1994) "A Practical Test for Univariate and Multivariate Normality," mimeo, Nuffield College, Oxford.

Doornik, J. A., and D. F. Hendry (1994) PcGive Professional 8.0: An Interactive Econometric Modelling System, London, International Thomson Publishing.

Durbin, J., and G. S. Watson (1950) "Testing for Serial Correlation in Least Squares Regression. I," Biometrika, 37, 3 and 4, 409-428. 
Durbin, J., and G. S. Watson (1951) "Testing for Serial Correlation in Least Squares Regression. II," Biometrika, 38, 1 and 2, 159-178.

Engle, R. F. (1982) “Autoregressive Conditional Heteroscedasticity with Estimates of the Variance of United Kingdom Inflation,” Econometrica, 50, 4, 987-1007.

Engle, R. F., and C. W. J. Granger (1987) "Co-integration and Error Correction: Representation, Estimation, and Testing," Econometrica, 55, 2, 251-276.

Engle, R. F., and D. F. Hendry (1993) "Testing Super Exogeneity and Invariance in Regression Models," Journal of Econometrics, 56, 1/2, 119-139.

Ericsson, N. R. (1992) "Cointegration, Exogeneity, and Policy Analysis: An Overview," Journal of Policy Modeling, 14, 3, 251-280.

Ericsson, N. R., J. Campos, and H.-A. Tran (1990) "PC-GIVE and David Hendry's Econometric Methodology," Revista de Econometria, 10, 1, 7-117.

Ericsson, N. R., D. F. Hendry, and H.-A. Tran (1994) "Cointegration, Seasonality, Encompassing, and the Demand for Money in the United Kingdom," Chapter 7 in C. P. Hargreaves (ed.) Nonstationary Time Series Analysis and Cointegration, Oxford, Oxford University Press, 179-224.

Filippides, A. A., P. E. Kyriakopoulos, and D. M. Moschos (1995) "Bank of Greece Monetary Policy Instruments," Bank of Greece Economic Bulletin, 6, 55-63.

Friedman, M. (1956) "The Quantity Theory of Money - A Restatement," Chapter 1 in M. Friedman (ed.) Studies in the Quantity Theory of Money, Chicago, University of Chicago Press, 3-21.

Godfrey, L. G. (1978) “Testing Against General Autoregressive and Moving Average Error Models when the Regressors Include Lagged Dependent Variables," Econometrica, 46, 6, 1293-1301.

Harvey, A. C. (1981) The Econometric Analysis of Time Series, Oxford, Philip Allan.

Hendry, D. F. (1988) "The Encompassing Implications of Feedback versus Feedforward Mechanisms in Econometrics," Oxford Economic Papers, 40, 1, 132-149.

Hendry, D. F. (1995) Dynamic Econometrics, Oxford, Oxford University Press.

Hendry, D. F., and J. A. Doornik (1994) "Modelling Linear Dynamic Econometric Systems," Scottish Journal of Political Economy, 41, 1, 1-33.

Hendry, D. F., and N. R. Ericsson (1991a) "An Econometric Analysis of U.K. Money Demand in Monetary Trends in the United States and the United Kingdom by Milton Friedman and Anna J. Schwartz," American Economic Review, 81, 1, 8-38.

Hendry, D. F., and N. R. Ericsson (1991b) "Modeling the Demand for Narrow Money in the United Kingdom and the United States," European Economic Review, 35, 4, 833-886 (with discussion).

Hendry, D. F., and G. E. Mizon (1993) "Evaluating Dynamic Econometric Models by Encompassing the VAR," Chapter 18 in P. C. B. Phillips (ed.) Models, Methods, and Applications of Econometrics: Essays in Honor of A. R. Bergstrom, Cambridge, Massachusetts, Basil Blackwell, 272-300.

Hendry, D. F., and G. E. Mizon (1995) “The Role of Exogeneity in Economic Policy 
Analysis," mimeo, Nuffield College, Oxford.

Hendry, D. F., and R. M. Starr (1993) "The Demand for M1 in the USA: A Reply to James M. Boughton,” Economic Journal, 103, 420, 1158-1169.

Jarque, C. M., and A. K. Bera (1980) "Efficient Tests for Normality, Homoscedasticity and Serial Independence of Regression Residuals," Economics Letters, 6, 3, 255-259.

Johansen, S. (1988) "Statistical Analysis of Cointegration Vectors," Journal of Economic Dynamics and Control, 12, 2/3, 231-254.

Johansen, S. (1991) "Estimation and Hypothesis Testing of Cointegration Vectors in Gaussian Vector Autoregressive Models," Econometrica, 59, 6, 1551-1580.

Johansen, S. (1992a) "Cointegration in Partial Systems and the Efficiency of Singleequation Analysis," Journal of Econometrics, 52, 3, 389-402.

Johansen, S. (1992b) "Testing Weak Exogeneity and the Order of Cointegration in UK Money Demand Data," Journal of Policy Modeling, 14, 3, 313-334.

Johansen, S. (1995) Likelihood-based Inference in Cointegrated Vector Autoregressive Models, Oxford, Oxford University Press.

Johansen, S., and K. Juselius (1990) "Maximum Likelihood Estimation and Inference on Cointegration - With Applications to the Demand for Money," Oxford Bulletin of Economics and Statistics, 52, 2, 169-210.

Judd, J. P., and J. L. Scadding (1982) "The Search for a Stable Money Demand Function: A Survey of the Post-1973 Literature," Journal of Economic Literature, 20, 3, 993-1023.

Juselius, K. (1993) "VAR Modelling and Haavelmo's Probability Approach to Macroeconomic Modelling," Empirical Economics, 18, 4, 595-622.

Kamin, S. B., and N. R. Ericsson (1993) "Dollarization in Argentina," International Finance Discussion Paper No. 460, Board of Governors of the Federal Reserve System, Washington, D.C., November.

Kremers, J. J. M., N. R. Ericsson, and J. J. Dolado (1992) "The Power of Cointegration Tests," Oxford Bulletin of Economics and Statistics, 54, 3, 325-348.

MacKinnon, J. G. (1991) "Critical Values for Cointegration Tests," Chapter 13 in R. F. Engle and C. W. J. Granger (eds.) Long-run Economic Relationships: Readings in Cointegration, Oxford, Oxford University Press, 267-276.

MacKinnon, J. G., and H. White (1985) "Some Heteroskedasticity-consistent Covariance Matrix Estimators with Improved Finite Sample Properties," Journal of Econometrics, 29, 3, 305-325.

Milbourne, R. (1983) “Optimal Money Holding Under Uncertainty,” International Economic Review, 24, 3, 685-698.

Miller, M. H., and D. Orr (1966) "A Model of the Demand for Money by Firms," Quarterly Journal of Economics, 80, 3, 413-435.

Nicholls, D. F., and A. R. Pagan (1983) "Heteroscedasticity in Models with Lagged Dependent Variables," Econometrica, 51, 4, 1233-1242.

Osterwald-Lenum, M. (1992) “A Note with Quantiles of the Asymptotic Distribution of 
the Maximum Likelihood Cointegration Rank Test Statistics," Oxford Bulletin of Economics and Statistics, 54, 3, 461-472.

Prodromidis, K. P. (1984) "Determinants of Money Demand in Greece, 1966 I - 1977 IV," Kredit und Kapital, 17, 3, 352-370.

Psaradakis, Z. (1993) "The Demand for Money in Greece: An Exercise in Econometric Modelling with Cointegrated Variables," Oxford Bulletin of Economics and Statistics, 55, 2, 215-236.

Ramsey, J. B. (1969) "Tests for Specification Errors in Classical Linear Least-squares Regression Analysis," Journal of the Royal Statistical Society, Series B, 31, 2, 350-371.

Smith, G. W. (1986) "A Dynamic Baumol-Tobin Model of Money Demand," Review of Economic Studies, 53, 3, 465-469.

Soumelis, G. (1995) "Greece: Reforming Financial Markets," OECD Observer, 193, $40-41$.

Stock, J. H. (1994) "Unit Roots, Structural Breaks and Trends," Chapter 46 in R. F. Engle and D. L. McFadden (eds.) Handbook of Econometrics, Amsterdam, North-Holland, Volume 4, 2739-2841.

Taylor, M. P. (1986) "From the General to the Specific: The Demand for M2 in Three European Countries," Empirical Economics, 11, 4, 243-261.

Tobin, J. (1956) "The Interest Elasticity of Transactions Demand for Cash," Review of Economics and Statistics, 38, 3, 241-247.

Wallis, K. F. (1974) "Seasonal Adjustment and Relations between Variables," Journal of the American Statistical Association, 69, 345, 18-31.

Watson, M. W. (1994) "Vector Autoregressions and Cointegration," Chapter 47 in R. F. Engle and D. L. McFadden (eds.) Handbook of Econometrics, Amsterdam, North-Holland, Volume 4, 2843-2915.

White, H. (1980) "A Heteroskedasticity-consistent Covariance Matrix Estimator and a Direct Test for Heteroskedasticity," Econometrica, 48, 4, 817-838. 